OPEN ACCESS

Edited by:

Attila Tarnok,

Fraunhofer Institute for Cell Therapy and Immunology (IZI), Germany

Reviewed by:

Daniel Olive

Aix Marseille Université, France

Matteo Bellone,

San Raffaele Hospital (IRCCS), Italy

${ }^{*}$ Correspondence:

Lara Gibellin

lara.gibellini@unimore.it

tThese authors have contributed equally to this work

Specialty section:

This article was submitted to Cancer Immunity and Immunotherapy, a section of the journal Frontiers in Immunology

Received: 11 December 2019 Accepted: 03 March 2020

Published: 20 March 2020

Citation:

Gibellini L, De Biasi S, Porta C, Lo Tartaro D, Depenni R, Pellacani G, Sabbatini R and Cossarizza A (2020)

Single-Cell Approaches to Profile the Response to Immune Checkpoint Inhibitors. Front. Immunol. 11:490. doi: 10.3389/fimmu.2020.00490

\title{
Single-Cell Approaches to Profile the Response to Immune Checkpoint Inhibitors
}

\begin{abstract}
Lara Gibellini $^{1 * t}$, Sara De Biasi ${ }^{1+}$, Camillo Porta ${ }^{2}$, Domenico Lo Tartaro ${ }^{1}$, Roberta Depenni ${ }^{3}$, Giovanni Pellacani ${ }^{4}$, Roberto Sabbatini ${ }^{3}$ and Andrea Cossarizza ${ }^{1,5}$

1 Department of Medical and Surgical Sciences for Children and Adults, University of Modena and Reggio Emilia, Modena, Italy, ${ }^{2}$ Department of Internal Medicine and Therapeutics, Division of Translational Oncology, IRCCS Istituti Clinici Scientifici Maugeri, University of Pavia, Pavia, Italy, ${ }^{3}$ Department of Oncology, Hematology, University of Modena and Reggio Emilia, Modena, Italy, ${ }^{4}$ Department of Surgery, Medicine, Dentistry and Morphological Sciences, University of Modena and Reggio Emilia, Modena, Italy, ${ }^{5}$ Section of Modena, Istituto Nazionale per le Ricerche Cardiovascolari, Bologna, Italy
\end{abstract}

Novel treatments based upon the use of immune checkpoint inhibitors have an impressive efficacy in different types of cancer. Unfortunately, most patients do not derive benefit or lasting responses, and the reasons for the lack of therapeutic success are not known. Over the past two decades, a pressing need to deeply profile either the tumor microenvironment or cells responsible for the immune response has led investigators to integrate data obtained from traditional approaches with those obtained with new, more sophisticated, single-cell technologies, including high parameter flow cytometry, single-cell sequencing and high resolution imaging. The introduction and use of these technologies had, and still have a prominent impact in the field of cancer immunotherapy, allowing delving deeper into the molecular and cellular crosstalk between cancer and immune system, and fostering the identification of predictive biomarkers of response. In this review, besides the molecular and cellular cancer-immune system interactions, we are discussing how cutting-edge single-cell approaches are helping to point out the heterogeneity of immune cells in the tumor microenvironment and in blood.

\section{Keywords: immunotherapy, immune checkpoint, single-cell technologies, cancer, immune system}

\section{INTRODUCTION}

Immune checkpoints are critical regulators of the immune system which modulate the duration and amplitude of immune responses to maintain self-tolerance and prevent autoimmunity. Among immune checkpoints, cytotoxic T lymphocyte antigen-4 (CTLA-4, or CD152), programmed death-1 (PD-1, or CD279) and programmed death ligand-1 (PD-L1, or CD274) have been intensively studied and antibodies against these molecules have been developed to successfully reinvigorate $\mathrm{T}$ cell functions and provide a durable immune response. Antibodies against immune checkpoints have demonstrated impressive efficacy, and now constitute the backbone of systemic therapy in different malignancies (1).

Despite considerable advancements in clinical care, epidemiologic data and ongoing clinical trials suggest that most patients receiving immune checkpoint inhibitors (ICI) do not derive benefit or stable and lasting responses. The mechanisms at the basis of this lack of responsiveness are multiple, and still not completely known. Over the past years, accumulating evidence suggested that the elevated neoantigen load (i.e., the number of antigens actually targeted by $\mathrm{T}$ cells) may have a 
robust relationship with the response to ICI (2). In particular, the more is the neoantigen load, the better is the response to therapy. However, the intensity and efficacy of the immune response can vary upon neoantigens' clonality. It seems that neoantigens derived from clonal mutations, which appear early during tumorigenesis, may elicit more effective tumor responses than neoantigens derived from subclonal mutations, which are acquired later in tumorigenesis (3). This means that intratumoral heterogeneity may impact the response to ICI. Moreover, several biophysical matters occur in the binding and recognition between peptide-MHC complex and T cell receptor (TCR) (4), and current prediction algorithms are still unable to precisely define TCR binding capacity for specific neoantigens (2). An additional layer of complexity originates from the fact that $\mathrm{T}$ cells, which are the main mediator of anti-tumor immunity, are extremely heterogenous in the tumor microenvironment (TME), and that beyond $\mathrm{T}$ cells many other types of immune cells are present in the tumor tissue that could affect response to ICI (4). Furthermore, an anticancer immune response may be impaired also by a number of other factors, mainly immune cells polarized toward an immune suppressive phenotype (5).

Taken together, these observations suggest that most, if not all, of these components are involved in the clinical response to ICI, and that the identification of the mechanism(s) at the basis of such response is crucial, both to provide important insights into the molecular and cellular crosstalk between cancer and immune system, and possibly foster the identification of predictive biomarkers of response (6). In this scenario, recently several novel single-cell technologies have been used to draw an in-depth characterization of tumor and immune system ecosystems in different malignancies. Here, we first describe the interactions between tumor and immune cells and then give an overview of the cutting-edge single-cell approaches mainly used to interrogate cancer immunity both in the tumor microenvironment and in the blood. We also cover and discuss how single-cell analysis have revealed the vast heterogeneity characterizing intra-tumoral immune cells, mainly $\mathrm{T}$ cells, and how this knowledge is critical to understand the role of different cell states and phenotypes in the response to immune checkpoint inhibitors.

\section{IMMUNE SYSTEM AND CANCER \\ Cancer Immunosurveillance and Immunoediting}

The long-standing theory of immune surveillance suggests that cells and tissues are regularly monitored by the immune system, which is responsible for recognizing and eliminating the vast majority of nascent cancer cells. The interactions between cancer and the immune system are regulated by a complex network of biological pathways, and start during the early steps of carcinogenesis, when normal cells acquire biological capabilities which allow them to evolve progressively to a neoplastic state. Such capabilities are commonly known as hallmarks of cancer, and among them the ability to evade immune system is crucial to guarantee cancer cell survival and tumor progression (7).
Over the past years, accumulating evidences, both from murine models and clinical epidemiology, have validated the concept of cancer immunosurveillance, demonstrating that the immune response acts as a barrier to tumor development and progression, and is a critical determinant of susceptibility to tumors (8-13). This action is exerted through at least three distinct mechanisms: (i) protection of the host from viral infections, and thus suppression of tumors of viral etiology; (ii) prevention or resolution of inflammation, which facilitates tumorigenesis; (iii) identification and elimination of cancer cells, in certain tissues and on the basis of the expression of tumorspecific antigens (14). In particular, deficiencies in the number or functionality of CD8+ cytotoxic T lymphocytes (CTLs), CD4+ type-1 T helper (Th1) cells, natural killer (NK) cells, natural killer T (NKT) cells, B cells, or $\gamma \delta \mathrm{T}$ cells lead to increased susceptibility to carcinogen-induced tumors and spontaneous tumors development $(9,11,15,16)$. Similarly, unsensitivity to interferons (IFNs) or lack of perforin, interleukin (IL)-12, tumor necrosis factor (TNF)- $\alpha$ or IL-1 $\beta$ are associated with increased tumor susceptibility $(10,11,17-20)$.

Reinforcing this notion, clinical epidemiology supports the existence of antitumoral immune response in some types of cancer. Firstly, evidence for immunosurveillance can be found in patients with acquired immunodeficiencies, like that caused by the human immunodeficiency virus (HIV), the cause of AIDS, who have an increased frequency of virus-associated malignancies, including Kaposi's sarcoma, lymphomas, urogenital cancers, and cervical cancers due to different strains of papillomavirus (21). Secondly, higher cancer prevalence has been observed in transplanted recipients treated with immunosuppressive drugs. Immunosuppression to prevent transplant rejection is associated with a 3- to 100 -fold increased risk of developing certain types of cancer, mainly lymphomas (22). However, solid tumors with no viral etiology also occur with increased frequency. For example, patients receiving renal transplant have a 3 -fold increase in the incidence of cancers respect to the general population, and a 200 -fold increase of skin cancers (23). Patients with liver transplant also display a greater incidence of malignancies, including head and neck cancers, and skin cancers $(24,25)$.

Along with clinical epidemiology, other evidences support the theory of cancer immunosurveillance, including the identification of tumor antigens and of antibodies against those antigens. In cancer patients, humoral immune response has been detected against more than a hundred tumor-associated antigens, thus indicating that the immune system is well able to fight against cancer (26). However, whether or not the identification and quantification of these antibodies has a clear diagnostic and/or prognostic relevance is still unclear. Other spontaneous immune responses against cancer cells have been described in paraneoplastic autoimmune syndromes, caused by the activation of an immune response against selfantigens expressed on cancer cells. Paraneoplastic autoimmune syndromes are often caused by cross-reactivity between the antitumor immune response and antigens present in the nervous system, and the onset of neurologic symptoms typically precedes the diagnosis of a formerly undetected tumor (27). 
Advancements made all over the past two decades have demonstrated that the immune system not only defends the host against tumor development, but also edits tumor immunogenicity, in a process referred to as cancer immunoediting. In its most complicated form, cancer immunoediting proceeds through three phases, termed elimination, equilibrium and escape. During the elimination phase, both innate and adaptive immune system collaborate to recognize and kill neoplastic cells. Cancer clones which survive the elimination phase can then progress through the equilibrium phase, in which tumor growth is limited, but cellular immunogenicity is edited by the adaptive immune system, mainly lymphocytes. During this phase, the pressure of the immune system together with the genetic instability of tumor cells can lead to the selection of neoplastic subclones with low immunogenicity, which can enter into the escape phase and evade the immune recognition. A large number of mechanisms operate to enable tumor immune escape by interfering with almost every step required to generate an effective immune response, i.e., the: (i) tumor capacity to downregulate antigens and/or MHC I; (ii) tumor expression and/or secretion of immunosuppressive molecules and/or antiphagocytosis signals; (iii) tumor modulation of lymphocytes' metabolism; (iv) recruitment of immune cells that actively mediate tolerance, or even promote tumor growth (28).

Since Virchow noted the presence of lymphocyte infiltration in solid tumors in 1863 (29), additional support for cancer immunosurveillance and immunoediting is evident in uncountable reports that describe the presence of immune cells infiltrating the tumors, and that correlate their frequency with patient prognosis. The presence of $\mathrm{T}$ cells inside tumors was observed, in late 1990's, in patients with melanoma, and then described for several other malignancies, including ovarian, colorectal (CRC) or lung cancer (30-36). From then on, a great attention has been paid to investigate the role of tumor-infiltrating lymphocytes (TILs). This effort resulted in the identification of TILs frequency as a bona fide indicator of improved prognosis and increased overall survival for several types of tumors.

Recent advancements in the characterization of the immune context within the tumor microenvironment have revealed that different classes of the so-called tumor immune environment (TIME) exist that are associated to tumor initiation and could affect the response to therapies (37). The TIME varies greatly across individuals and over distinct cancers. However, despite variability, two main classes can be described, which differ on the basis of composition, functional status and spatial distribution of immune cells. Infiltrated-excluded TIMEs are populated by immune cells mainly along the tumor margins, and are relatively poor of CTLs in the tumor core (37). Moreover, CTLs from this kind of TIME typically display low expression of activation or cytotoxicity markers, including granzyme(GZM)-B and IFN- $\gamma$ (37). Conversely, infiltrated-inflamed TIMEs are characterized by large immune infiltration among neoplastic cells, with a high frequency of CTLs expressing GZM-B, IFN- $\gamma$, and PD-1. In some cases, infiltrated-inflamed TIMEs contain compartments which resemble tertiary lymphoid structures (TLSs), and act as sites of lymphoid recruitment and immune activation (38). Such compartments are generally located at the invasive tumor margin and in the stroma, and include naïve and activated $\mathrm{T}$ cells, regulatory T (Treg) cells, B cells and dendritic cells (DCs) (37). Over the past years, the immune network of the TME has become a focus of cancer research and therapeutics development, and the need to understand its great complexity and diversity in this context is now compelling.

\section{Immune Checkpoints and Their Inhibitors}

Immune checkpoints are molecules expressed on $\mathrm{T}$ cell plasma membrane able to inhibit or activate the development or execution of effector functions exerted by cytotoxic or proinflammatory T cells. Among immune checkpoints, CTLA-4 and PD-1 have been most actively studied in the field of clinical cancer immunotherapy.

CTLA-4 and CD28 are homologous molecules expressed by $\mathrm{CD} 4+$ and CD8+ T cells, which mediate antagonistic functions in $\mathrm{T}$ cell activation, and share two ligands, namely B7-1 (CD80) and B7-2 (CD86), expressed on antigen-presenting cells (APCs). CD28 interacts with the CD80 dimer with relatively high affinity and the CD86 monomer with lower affinity, to mediate $\mathrm{T}$ cell activation in conjunction with TCR signals. Conversely, CTLA4 interacts with both ligands with higher affinity and avidity than CD28, to inhibit T cell activation. CTLA-4 is constitutively expressed on Treg cells or induced following T-cell activation via CD28 and TCR signaling (39). The humanized anti-CTLA4 antibody ipilimumab was approved by the United States Food and Drug Administration (FDA) in 2011. It blocks the interaction between CTLA-4 and its ligands expressed by APCs, thereby preventing the transmission of inhibitory signals to CTLA-4expressing $\mathrm{T}$ cells. Although the blocking of inhibitory signals is the main mechanistic contributor to ipilimumab functions, other still poorly known mechanisms are involved. For example, the effects of anti-CTLA-4 on Treg is still matter of debate. Indeed, the binding of CTLA- 4 by ipilimumab on Treg within the tumor tissue would likely promote Treg depletion by antibodydependent cellular cytotoxicity (ADCC) and phagocytosis by NK cells and macrophages $(40,41)$. Recently it was found that both ipilimumab and tremelimumab, another anti-CTLA-4 drug, increase infiltration of intratumoral CD4+ and CD8+ T cells without significantly changing or depleting FOXP3 + cells within the TME (42). Nonetheless, regardless the mechanism of action, ipilimumab demonstrated impressive anti-tumor activity in several clinical settings in metastatic melanoma $(43,44)$.

Along with CTLA-4, the PD-1/PD-L1 system constitutes another immune checkpoint pathway mainly operating by controlling immune homeostasis. However, while transient expression of PD-1 is a feature of normal T lymphocyte activation, persistent antigen exposure leads to a sustained expression of PD-1 with a gradual loss of effector functions which are characteristic of exhausted T cell (45). PD-1 mediates an inhibitory signal in $\mathrm{T}$ cells after binding to its ligands, PD-L1 and PD-L2, which are expressed on APCs and cancer cells (46). The blockade of PD-1/PD-L1 pathway with anti-PD-1 or antiPD-L1 antibodies, can successfully reinvigorate $\mathrm{T}$ cell functions and provide a durable response in different malignancies. There 
are currently six inhibitors of the PD-1/PD-L1 pathway, namely nivolumab, pembrolizumab, cemiplimab (directed against PD1), and atezolizumab, avelumab and durvalumab (directed against PD-L1), which have been approved by the FDA for the treatment of tumors like melanoma, lung cancer, renal-cell carcinoma (RCC), microsatellite instability-high CRC, classical Hodgkin lymphoma, head and neck squamous cell cancer (HNSCC), hepatocellular carcinoma (HCC), bladder cancer, gastro-oesophageal cancer, and unresectable or metastatic, microsatellite instability-high or mismatch repair deficient solid tumors (47).

The best examples of stable response are those observed in patients with advanced melanoma. In these patients, it was reported that 3-year overall survival was 34 and 52\% for ipilimumab and nivolumab, respectively (48). The 3-year overall survival was $60,55,41 \%$ for nivolumab plus ipilimumab, nivolumab alone, or ipilimumab alone (49). In advanced RCC, the 2-year overall survival of patients treated with nivolumab plus ipilimumab was $28 \%$, and complete responses were $11 \%$ (50-52). In other cancers, responses to immune checkpoint monotherapies were not as impressive as in melanoma. This means that despite considerable advancements in clinical care of some tumors, epidemiologic data and ongoing clinical trials suggest that most of the patients receiving ICI do not derive benefit or durable responses, and the mechanisms at the basis of this lack of responsiveness are multiple and still not completely known.

\section{SINGLE-CELL APPROACHES TO IMMUNE PROFILE}

Over the past two decades, a pressing need to deeply profile the TIME has led investigators to complement data obtained from traditional approaches, like immunohistochemistry, basic flow cytometry or measurements on bulk populations of cells, with data obtained with novel, more sophisticated, single-cell technologies. To date, a vast array of single-cell approaches, including high-parameter flow cytometry, deep sequencing, and high-resolution imaging are available to unmask cellular heterogeneity and to try to identify actionable hallmarks of efficient anticancer immunotherapy. In Table $\mathbf{1}$ a general overview of single-cell technologies is provided together with their advantages and disadvantages.

\section{High-Parameter Flow Cytometry}

Last advances in proteomics and genomics are paving the way to comprehend the complexity and the heterogeneity of billions of specialized immune cells in cancer patients. For decades, immunologists relied mainly on flow cytometry, the first singlecell technique that now allows to study the expression and density of up to 30-40 antigens in a single-cell level. Flow cytometry is very popular technique used to measure physical and chemical characteristics of a population of cells/particles suspended in a fluid, and is routinely used both in basic research, and in clinical practice to perform cell count, determine cell phenotypes and functions allowing the monitoring of immune features in pathophysiological settings $(64,65)$. Flow cytometry is unmatched for its high throughput as several million cells can be analyzed in a few minutes. In addition, cells can be sorted achieving pure cell populations to perform further functional, metabolic and molecular analyses (66). Sample preparation for flow cytometry is relatively fast, but setting up a flow cytometry panel that includes 28-30 parameters takes a lot of time because of the need to optimize spectral overlap between fluorophores, and to choose best antibodies. These issues can be overcome by following precise rules applicable to panel design, and optimized panels published such as Optimized Multicolor Immunophenotyping Panels (OMIPs) (67-72). Together with fluorescent flow cytometry, mass cytometry (also called CyTOFCytometry by Time-Of-Flight) is a technology that allows simultaneous analysis of more than 40 different molecules, including cytokines and transcription factors, with minimal compensation $(53,54)$. This technique exploits the use of monoclonal antibodies conjugated with heavy-metal isotopes to stain cells and quadrupole time-of-flight mass spectrometer to perform the detection (73). Mass spectrometry is able to discriminate isotopes of different atomic weights with high accuracy, enabling more features to be assayed at the same time, so the quantity of reporter ions in a particular mass channel represents the marker expression with little signal overlap between parameters.

Among high-parameter single-cell technologies, at present flow cytometry is the gold standard. However, it reveals the different percentages of cell populations in different pathophysiological onsets barely identifying different clones (74). Flow cytometry perfectly captures the phenotype of cells, but fails to snap their biological complexity. The spectrum of phenotypic diversity of immune cells within the TME and in blood can better be appreciated by analyses at the single-cell level to explore cellular heterogeneity, in terms of gene expression and chromatin accessibility, that often confounds biomolecular variation from multi-omics approaches in bulk. Recently, the adaptation of high-parameter flow cytometry to imaging platforms took to the development of two promising technologies, known as Imaging Mass Cytometry (IMC), Co-detection by Indexing (CODEX) and multiepitope-ligand-cartography (MELC) $(55-57,75,76)$. The former is used to process tissues, employs antibodies tagged with lanthanides and combines a high resolution laser ablation system with CyTOF (77). IMC enables the study of cellcell interactions and of intercellular networks, thus providing information regarding the spatial distribution of cells within a tissue (57-59). CODEX employs oligonucleotide-conjugated antibodies. Although these technologies have not yet been applied to dissect immune responses in the field of cancer immunotherapy, the power will be used to investigate the role of immune cells in the TME.

\section{Single-Cell RNA Sequencing}

Single-cell RNA sequencing (scRNA-seq) technology provide a transformative view of cell-type-specific gene expression and allows to analyze hundreds of messenger RNAs (mRNAs) in a single experiment, enabling the reconstruction of a highresolution map of cells according to their molecular signature 
TABLE 1 | Advantages and disadvantages of the cutting-edge single-cell technologies to profile cancer immunity.

\begin{tabular}{|c|c|c|c|}
\hline Methodology & Advantages & Disadvantages & References \\
\hline $\begin{array}{l}\text { Flow } \\
\text { cytometry }\end{array}$ & $\begin{array}{l}\text { - Evaluation of protein, RNA and DNA at a single-cell level } \\
\text { simultaneously; } \\
\text { - Easy and fast sample preparation; } \\
\text { - Acquisition of sample is high-throughput and fast; } \\
\text { - A plethora of unsupervised and supervised data analysis } \\
\text { methods available (global data structure, cellular progression, } \\
\text { cellular diversity, signaling network inference, } \\
\text { correlative/predictive features of clinical outcome or sample } \\
\text { type); } \\
\text { - Possible to sort cells and perform further studies; } \\
\text { - The cost is cheap (more or less, US \$ } 0.10 \text { per cell). }\end{array}$ & $\begin{array}{l}\text { - Limit to 30-parameters at time; } \\
\text { - Spillover among different fluorescences; } \\
\text { - Quality control of the data needed; } \\
\text { - High level of expertise is needed to analyze data; } \\
\text { - No information on tissue structure; } \\
\text { - Acquisition of samples must occur in a few hours after } \\
\text { staining due to photo bleaching. }\end{array}$ & (53) \\
\hline $\begin{array}{l}\text { Mass } \\
\text { cytometry }\end{array}$ & $\begin{array}{l}\text { - Evaluation of protein, RNA and DNA at a single cell level } \\
\text { simultaneously (up to } 40 \text { parameters - theoretically around 100); } \\
\text { - Sample preparation is fast; } \\
\text { - Acquisition of sample is high-throughput; } \\
\text { - Metal-tagged samples can be run up to } 2 \text { weeks after staining } \\
\text { without notable loss of signal and can be cryopreserved up to } 1 \\
\text { month without affecting the data quality or staining integrity of } \\
\text { both surface and intracellular markers; } \\
\text { - A plethora of unsupervised and supervised data analysis } \\
\text { methods available (global data structure, cellular progression, } \\
\text { cellular diversity, signaling network inference, } \\
\text { correlative/predictive features of clinical outcome or } \\
\text { sample type). }\end{array}$ & $\begin{array}{l}\text { - Sample acquisition is not fast; } \\
\text { - Difficult to measure molecules that are expressed at } \\
\text { very low levels; } \\
\text { - Quality control of the data needed; } \\
\text { - Spillover between close isotopes; } \\
\text { - High level of expertise needed to analyse data; } \\
\text { - No information on tissue structure; } \\
\text { - Impossible to recover living cells after analysis; } \\
\text { - The cost is much higher than fluorescence-based flow } \\
\text { cytometry (more or less, several US dollars per cell). }\end{array}$ & (54) \\
\hline $\begin{array}{l}\text { Image-flow } \\
\text { cytometry }\end{array}$ & $\begin{array}{l}\text { - Evaluation of protein, RNA and DNA at a single cell level } \\
\text { simultaneously (up to } 12 \text { parameters); } \\
\text { - Easy and fast sample preparation; } \\
\text { - Up to } 10 \text { fluorescent images per cell; } \\
\text { - Images up to 60x magnification; } \\
\text { - Detailed localization of signal from fluorescent probes. }\end{array}$ & $\begin{array}{l}\text { - Sample acquisition is not fast; } \\
\text { - No information on tissue structure; } \\
\text { - High expertise is needed to analyse data; } \\
\text { - Only few software used to analyse data; } \\
\text { - Not possible to perform unsupervised analysis. }\end{array}$ & (55) \\
\hline $\begin{array}{l}\text { Histo- } \\
\text { cytometry }\end{array}$ & $\begin{array}{l}\text { - Technology is based on multiplexed antibody staining, tiled } \\
\text { high-resolution confocal microscopy, voxel gating, volumetric } \\
\text { cell rendering, and quantitative analysis; } \\
\text { - Gain positional and quantitative information on complex cellular } \\
\text { subsets/phenotypes (defined by multiple markers) directly in } \\
\text { tissue sections; } \\
\text { - Very high-resolution imaging and accurate signal 3D allocation. }\end{array}$ & $\begin{array}{l}\text { - } 6-8 \text { colors/parameters; } \\
\text { - Spillover between fluorochromes; } \\
\text { - Due to the lack of molecular level resolution, imaging } \\
\text { does not spatially separate neighboring fluorescent } \\
\text { molecules, instead colocalizing them to the same } \\
\text { voxel (volumetric pixel); } \\
\text { - Software dedicated to imaging; } \\
\text { - Low- throughput. }\end{array}$ & (56) \\
\hline $\begin{array}{l}\text { Imaging mass } \\
\text { cytometry }\end{array}$ & $\begin{array}{l}\text { - Analytical platforms that successfully couple high-density } \\
\text { analysis by mass cytometry to conventional histology; } \\
\text { - Comprehensive exploration of individual cell phenotypes, } \\
\text { cell-cell interactions, microenvironments, and morphological } \\
\text { structures within intact tissues. }\end{array}$ & $\begin{array}{l}\text { - } 1 \mu \mathrm{m} \text { spot size } \\
\text { - Sample preparation is slow and needs a lot of } \\
\text { technical advices; } \\
\text { - The rate of image acquisition by laser ablation is slow } \\
\text { ( } 1.5 \mathrm{~mm}^{2} \text { in } 2 \mathrm{~h} \text { ), and sets a practical limit to the extent } \\
\text { to which a slide can be scanned; } \\
\text { - Many tissue markers of clinical importance show } \\
\text { considerable intratumoral heterogeneity in their } \\
\text { distribution patterns; } \\
\text { - Data analysis remains challenging, and is performed } \\
\text { by particular and dedicated software (like HistoCAT). }\end{array}$ & $(57-59)$ \\
\hline $\begin{array}{l}\text { Single-cell } \\
\text { RNA } \\
\text { sequencing }\end{array}$ & $\begin{array}{l}\text { - Different methods developed in recent years allow to investigate } \\
\text { - } \text { single-cell transcriptomics; } \\
\text { CEL-Seq2) and five high-throughput methods (10x Chromium, } \\
\text { Drop-seq, Seq-Well, inDrops, and sci-RNA-seq); } \\
\text { - Standardized and optimized protocols; } \\
\text { - Very high-throughput; } \\
\text { - A plethora of data analysis methods available (global data } \\
\text { structure, cellular progression, cellular diversity, signaling } \\
\text { - } \text { - On the basis of the type of sequencing it is possible to identify } \\
\text { cell clonality, allelic expression, alternative splicing, RNA editing; } \\
\text { - 2,000-6,000 genes per cell for primary cells if SMART-seq2 is } \\
\text { used; 1,000-3,000 genes if Drop-seq or InDrop is used; }\end{array}$ & $\begin{array}{l}\text { - Long procedures to prepare cDNA libraries; } \\
\text { - Sample preparation is long (2 days of protocol); } \\
\text { - High cost of single cell sequencing (thousands of US \$ } \\
\text { - Der sample); } \\
\text { - Data analysis requires the use of highly advanced } \\
\text { bioinformatics methods; } \\
\text { - Quality control, normalization and imputation needed; } \\
\text { - Due to technical limitations and biological factors, } \\
\text { more complex than bulk RNA-seq data. } \\
\text { - The high variability of scRNA-seq data raises } \\
\text { computational challenges in data analysis. }\end{array}$ & $(60-62)$ \\
\hline
\end{tabular}


TABLE 1 | Continued

\begin{tabular}{|c|c|c|c|}
\hline Methodology & Advantages & Disadvantages & References \\
\hline & $\begin{array}{l}\text { - Low cost of sample preparation: } \$ 3-6 \text { per well (if SMART-seq2 } \\
\text { protocol is used); } \$ 0.05 \text { per cell (if DropSeq or InDrop protocol } \\
\text { is applied). }\end{array}$ & & \\
\hline $\begin{array}{l}\text { Single-cell } \\
\text { ATAC } \\
\text { sequencing }\end{array}$ & $\begin{array}{l}\text { - It interrogates the genome for accessibility to DNA binding } \\
\text { proteins in a single experiment; such challenge emphasizes the } \\
\text { need for informative features to assess cell heterogeneity at the } \\
\text { chromatin level; } \\
\text { - scATAC-seq experiments sample DNA, compared to } \\
\text { transcriptomic (scRNA-seq) data; } \\
\text { - Single-cell ATAC libraries are created from single cells that have } \\
\text { been exposed to the Tn5 transposase using one of the following } \\
\text { protocols: Single cells are individually barcoded by a } \\
\text { split-and-pool approach where unique barcodes added at each } \\
\text { step can be used to identify reads originating from each cell, } \\
\text { microfluidic droplet-based technologies are used to extract and } \\
\text { label DNA from each cell, or each single cell is deposited into a } \\
\text { multi-well plate for library preparation. } \\
\text { - A plethora of data analysis methods available. }\end{array}$ & $\begin{array}{l}\text { - Sample preparation is long ( } 2 \text { days of protocol); } \\
\text { Data analysis for expert requires the use of } \\
\text { bioinformatics methods. }\end{array}$ & $(61,63)$ \\
\hline
\end{tabular}

(66). The first example of single-cell digital gene expression profiling was published in 2009, and since then on, a continuous effort has been made to improve experimental protocols and bioinformatics pipelines, which are essential to process data $(60,78,79)$. A canonical scRNA-seq protocol involves several steps, including single cell isolation, cell lysis to obtain RNA, reverse transcription into the first-strand cDNA, second-strand synthesis, cDNA amplification, and sequencing (60-62).

Although single cells can be isolated by different techniques, the use of microdroplet-based microfluidics is now widely diffused among the majority of commercial platforms and allows the isolation of individual cells into aqueous droplets in a continuous oil phase. In every droplet, cells are lysed in a hypotonic buffer, and mRNAs are captured by poly$\mathrm{dT}$ primers. When reverse transcription takes place, cDNA molecules originated from a given individual cells are identified by using short DNA barcode tags. Then, second strands are generated, and the small amount of synthesized double-strand cDNA is amplified by means of conventional polymerase chain reaction (PCR) or in vitro transcription, depending on the technology. Some protocols improved read coverage across transcripts, which significantly enhances detailed analyses of alternative transcript isoforms and identification of single nucleotide polymorphisms (SNPs) with high sensitivity and accuracy (80). Eventually, sequencing is performed, and once reads are obtained, data are pre-processed and analyzed through clustering of cells, classification and cell trajectory assignment (78, 79). Concerning $\mathrm{T}$ cells, during the last years, several algorithms have also been developed to utilize scRNA-seq data to reconstitute TCR information. TCR is a heterodimer composed of two chains, $\alpha$ and $\beta$, which result from genetic recombination of the $\mathrm{V}(\mathrm{D}) \mathrm{J}$ genes, and is responsible for the specificity of each $\mathrm{T}$ cell against cognate antigens. The diversity of TCR $\alpha \beta$ repertoire is associated with efficient protection against several pathogens (81), and more recently, the clonality of both peripheral blood and tumor TCR $\alpha \beta$ repertoire has also been associated with improved clinical outcome under anti-PD-1 or anti-CTLA-4 immunotherapy (82-84).

Despite its numerous pros and great potential, scRNA-seq suffers from the caveat that mRNA and protein expression do not always directly correlate. For this reason, recent technological advances have been made to capture new cell types with a better resolution, and to detect simultaneously mRNAs and proteins. For example, Cellular Indexing of Transcriptomes and Epitopes by Sequencing (CITE-seq), RNA Expression and Protein Sequencing (REAP-seq), Antibody sequencing (Ab-seq) enable the measurement of proteins and mRNAs in individual cells, by using antibodies labeled with DNA barcodes instead of fluorochromes, thus avoiding the limitations dictated by the possible spectral overlap of fluorescent signals (85-87). Quantifying proteins together with mRNAs allows to overcome the lack of correlation that sometimes exists between mRNA and protein levels, thus providing a more readout of cellular phenotype, at the single-cell level. Indeed, proteins, not mRNAs, are the real targets of drugs, and mRNA abundance cannot necessarily resemble protein abundance (85). Moreover, in certain settings, the measurement of protein abundance is more sensitive for markers with low levels of mRNA transcripts (85). Thus, CITE-seq, REAP-seq, and Abseq give an unbiased view of the mRNA and protein profile at the single-cell level, which is necessary to precisely identify cellular function, and provide important insights into the pathophysiology of multiple disorders. However, sample preparation requires more than 2 days and cells need to be fixed or lysed, therefore excluding the possibility to perform further analysis (85-87).

Another possibility to investigate both mRNA and proteins is the combination of scRNA-seq and high-parameter flow cytometry. The combinatorial use of scRNA-seq and highparameter flow cytometry in the same sample would likely have a huge impact in the field of immunotherapy, as is associated with unique advantages to each method together with the advantage of using both methodologies. Whereas each technology uses 
unsupervised clustering to identify different populations, scRNAseq is totally unbiased as it analyses the expression of thousands of genes. Conversely, high-parameter flow-cytometry looks at 30-40 markers that are pre-selected based on a priori knowledge. Also, scRNA-seq allows transcriptomic analysis between individual cell subsets, including the use of Gene Set Enrichment Analysis (GSEA) and comparisons to human datasets. However, as already described, mRNA and protein do not always correlate, meaning that the information on protein expression delivered by high-parameter flow-cytometry is also central. However, to date, a few studies reported the combination of scRNA-seq and CyTOF to profile the tumor immune microenvironment $(88,89)$.

\section{Single-Cell ATAC-Seq}

The Assay for Transposase-Accessible Chromatin using sequencing (ATAC-seq) is a method for assessing genome-wide chromatin accessibility. ATAC-seq identifies accessible DNA regions by probing accessible chromatin with hyperactive mutant Tn5 transposase that inserts sequencing adapters into open regions of the genome (90). Single cell ATAC-seq (scATACseq) measures chromatin accessibility enabling marker-free identification of cell type-specific cis- and trans-regulatory elements and mapping of disease-associated enhancer activity and reconstruction of trajectories of cellular differentiation, and has been used to map gene regulation in cell-to-cell variability and rare cell phenotypes, including in healthy and malignant immune cells $(61,63)$.

\section{The Analysis of Single-Cell Data}

Single-cell technologies generate huge amount of information that allow the exploration of cellular diversity at unprecedented depth and throughput. For this reason, one of the major analytical challenge is how to visualize and understand this highdimensional datasets originating from high dimensional flow cytometry, scRNA-seq and scATAC-seq. Data generated by highdimensional flow cytometry (up to 30 parameters in several million cells) can no longer be analyzed by using classical manual analysis techniques involving the use of bidimensional dot plots (91). Manual gating analyses is hard to reproduce, as is subjective and biased, and for large data set is extremely time consuming. Large datasets are computationally demanding, and therefore require the development and the application of novel techniques.

Computational flow cytometry provides a set of packages to analyze and visualize large amount of cells in an unbiased manner (92). These tools are automated, meaning that the quality of data is fundamental to get rid of false positive. For this reason, before analyzing high-parameter flow cytometry datasets, files need to be perfectly compensated, cleaned from the presence of aggregates and turbulences during acquisition. Only after this step, data can be analyzed by unsupervised tools $(93,94)$.

scRNA-seq requires pre-processing of data based on quality control performance and alignment (78). Several efforts have been made from bioinformaticians to develop and optimize new software and packages able to provide insights on the complex biology and dynamics of cells (66). Most software provide information regarding identification and characterization of cell types and their spatial organization in time (78). A canonical pipeline of data analysis firstly requires data visualization. There are methods based on dimensionality reduction techniques, including principal component analysis (PCA), t-distributed stochastic neighbor embedding ( $t-S N E)$, One-Dimensional SoliExpression by Nonlinear Stochastic Embedding (ONE-sense), Uniform Manifold Approximation and Projection (UMAP), that aim to preserve the main structure of data while reducing a highdimensional data description to a lower-dimensional projection (95-97). An example of the analysis of the same data by using PCA, t-SNE, and UMAP is reported in Figure 1. In addition, clustering-based techniques are available that group cells into cell type clusters in the original, high-dimensional space and subsequently use visualization algorithms to represent these cell type clusters in a lower-dimensional space $(93,98,99)$.

Secondly, differences in gene expression level between populations need to be analyzed. To this purpose, specialized methods have been designed for single-cell data that considers single cell features such as technical dropouts and shape of the distribution (100).

Thirdly, the software Monocle and Wanderlust independently introduced the concept of "pseudotemporal analysis," in which scRNA-seq data are collected from a population of cells undergoing a dynamic biological process and then computationally ordered into a trajectory that reflects the continuous changes in gene expression that occur from the beginning to the end of the process (101-103). Pseudotime trajectories allow to identify genes that exhibit differential expression over the course of the biological process and cluster them based on their expression dynamics. As of February 2020, more than seventy trajectory inference tools have already been developed (104).

\section{THE WORKFLOW OF SINGLE-CELL EXPERIMENT}

Regardless of the specific technology employed to generate a particular dataset, a common workflow can be formulated which involves multiple steps linking the initial study design to the final correlation to clinical data. A typical pipeline for single-cell experiments is reported in Figure 2. An accurate experimental planning is imperative to avoid technical issues and improve scientific reproducibility. Several professionals, including the statistician, the bioinformatician, the biologist and the clinician should be involved at this step to: (i) define the biological question; (ii) find patients; (iii) calculate the sample size; (iv) define the number of replicates; (v) decide the number of cells; (vi) define the sequencing depth (in the case of scRNAseq or sc-ATACseq experiments); (vii) choose the appropriate equipment (105). At this stage, experimental protocols should be standardized, and appropriate positive and negative controls should be selected to ensure good quality results. Then, experiment is performed and raw data are generated. Alongside, data pre-processing is performed. Quality control involves the examination of data, their possible transformation and normalization, the check for technical issues, batch effects or 


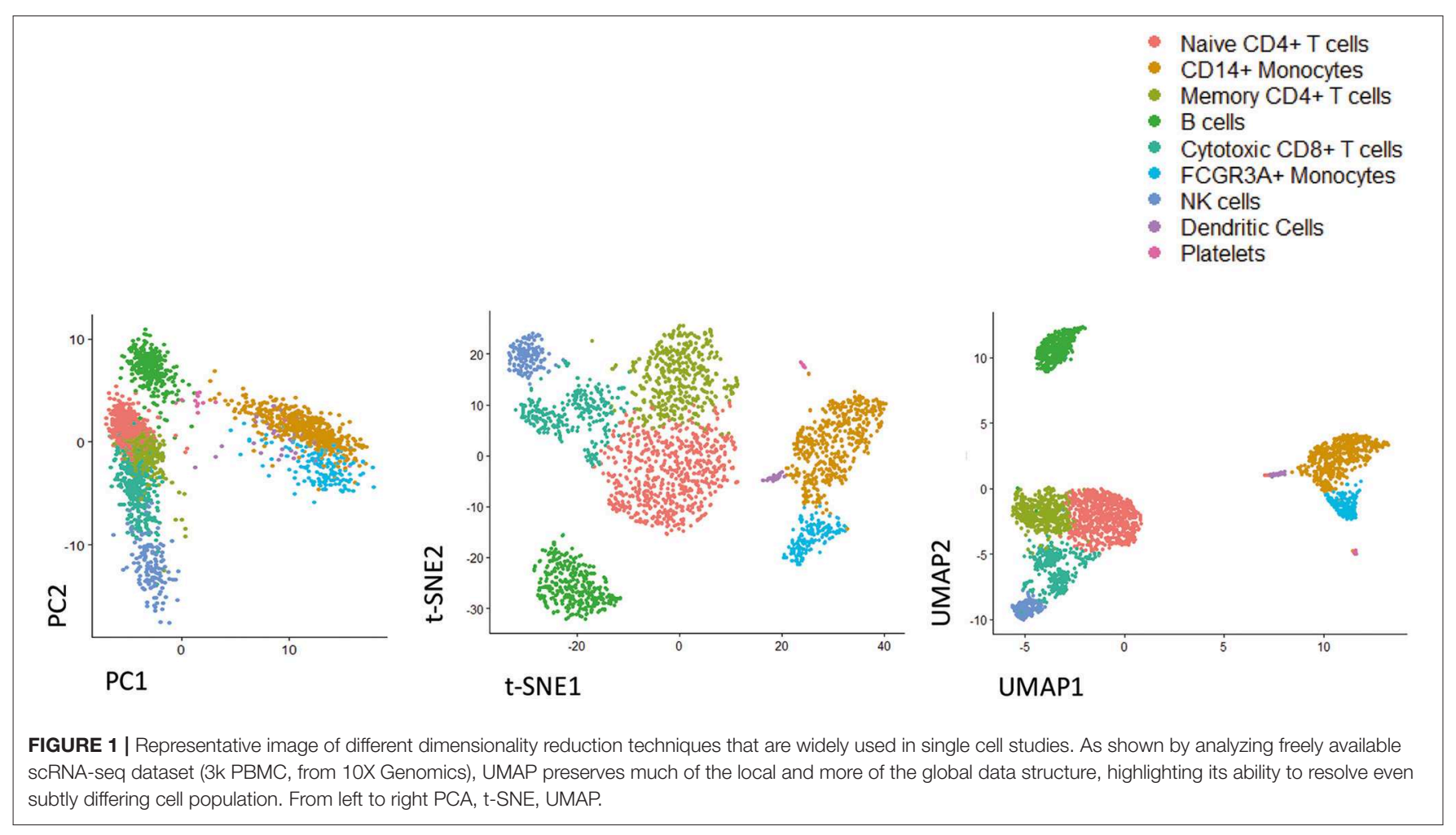

unexpected results. At the end of the entire process, clean data need to be visualized and analyzed by computational approaches to identify clusters and trajectories, and potentially derive novel predictive biomarkers of response to ICI.

\section{DATA FROM SINGLE-CELL STUDIES}

\section{Immune Cells in the Tumor Microenvironment}

Tumors contain different cell populations in endless evolution. This diversity is commonly referred to as tumor heterogeneity, and is considered the main driver of resistance to therapy and metastasis (106). The full comprehension of this heterogeneity would be extremely important to optimize existing therapeutic intervention and find new strategies to break down relapses and mortality. The recent development of technologies based on sequencing individual cells has been crucial to address tumor heterogeneity and to elucidate how cells are organized into multicellular systems. Single cell profiles not only revealed that human tumors comprise subpopulations of genetically different diverse malignant cells, but also that a profusion of different cell types from the surrounding tissues and the immune system, each with a precise role in pathogenicity, is present within the $\operatorname{TME}(106,107)$. The immune components of the tumor microenvironment in different kind of malignancies, including non-small cell lung cancer (NSCLC), clear cell RCC (ccRCC), breast cancer (BC), HCC, glioblastoma multiforme (GMB), microsatellite instability-stable CRC have been recently annotated and finely characterized $(88,108-111)$. In general, in the majority of these tumors, immune cells were mostly $\mathrm{T}$ cells, whereas myeloid cells, B cells and NK cells were found at lower frequencies (108-111). Only GMB had higher levels of CD68+ myeloid cells if compared to T cells (88).

In NSCLC tumor samples, different subsets of CD8 $+\mathrm{T}$ cells, conventional $\mathrm{CD} 4+\mathrm{T}$ cells, and Treg cells have been found (109). Each subset is characterized by a precise gene expression signature, which reflects a specific functional status. Two main clusters were found at high frequency: (i) exhausted $\mathrm{CD} 8+\mathrm{T}$ cells, characterized by increased expression of effector molecules, including GZM-A, granulysin (GNLY), perforin (PRF), GZM-B, NKG7, and inhibitory receptors, like lymphocyte activating (LAG)-3 (CD223), T cell immunoreceptor with Ig and ITIM domains (TIGIT), PD-1, and CTLA-4; (ii) suppressive CD4+ Treg cells, characterized by increased expression of costimulatory molecules, including $\mathrm{CD} 28$ and inducible $\mathrm{T}$ cell costimulatory (ICOS or CD278), and inhibitory receptors like CTLA-4 and TIGIT (109). Moreover, two CD8+ T cell subsets exhibited a functional state that precede exhaustion, and is indeed called pre-exhaustion state. These subsets do not express CTLA-4, and express mild levels of TIGIT, PD1 , and the transcription factor TOX, which is a critical driver of exhaustion (112-115). Whether or not pre-exhausted subsets could be more effectively reinvigorated by ICI than fully exhausted subsets is still not known. Furthermore, the expression level of PD-1 or other inhibitory receptors does not necessarily correlate with exhaustion-dependent dysfunction. It was indeed reported that tissue-resident memory $\mathrm{T}\left(\mathrm{T}_{\mathrm{RM}}\right)$ cells expressing PD-1, T-Cell Immunoglobulin And Mucin DomainContaining Protein-3 (TIM-3) and negative for CD127 (the $\alpha$ chain of the IL-7 receptor), which are present in lung 


\section{Path to biomarker discovery: computational workflow for single-cell experiments}

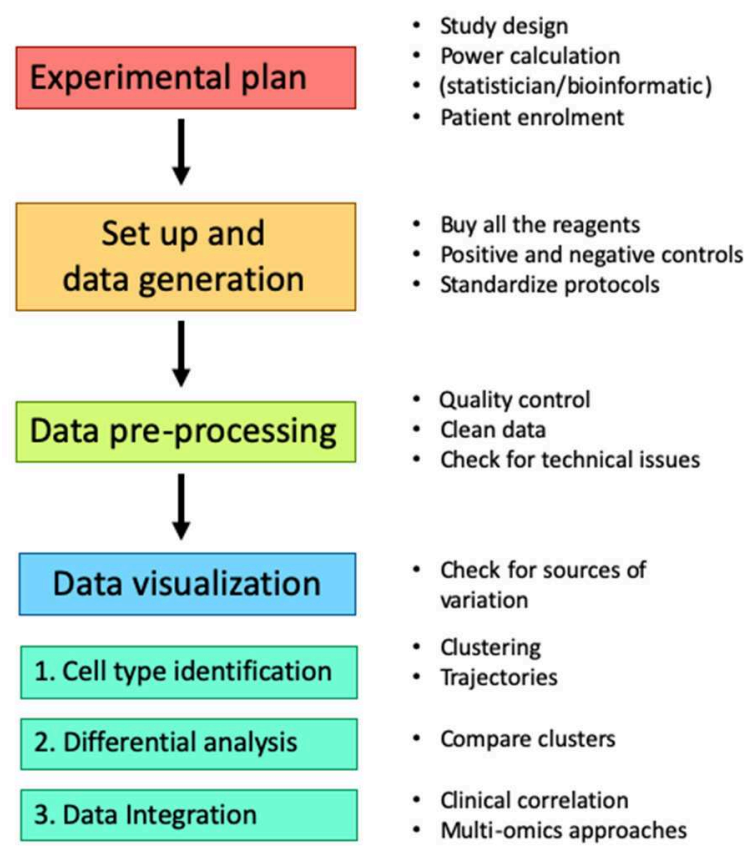

FIGURE 2 | Workflow for canonical single-cell experiment.

tumors, proliferate, can upregulate TCR activation-induced genes, exhibit a transcriptional signature indicative of effector, survival, and tissue-residency properties, and produce cytokines, like IL-2, IFN- $\gamma$ and TNF- $\alpha$ (116). In early-stage triple-negative $\mathrm{BC}$, among $\mathrm{CD} 8+\mathrm{T}$ cells infiltrating the TME, $\mathrm{T}_{\mathrm{RM}}$ cells display high levels of genes encoding for cytotoxic molecules, including $G Z M B$ and $P R F 1$, high levels of genes encoding for inhibitory checkpoint, as well as high levels of genes associated with proliferation (117). This means that the expression of inhibitory receptors is not a unique feature of exhausted $\mathrm{T}$ cells as several highly functional effector cells also express those receptors. This also means that exhausted $\mathrm{T}$ cells are heterogenous, and that $\mathrm{T}$ cell exhaustion, as well as T cell dysfunctionality, is a gradual, rather than a discrete, state (118).

In ccRCC, in-depth immunophenotyping analysis identified the main immune cell types in both $\mathrm{T}$ cells and tumorassociated macrophages (TAMs) (108). Concerning T cells, eight CD4+ clusters, eleven CD8+ clusters, one CD4+/CD8+ double positive cluster, and one CD4-/CD8- double negative cluster were identified (108). Notably, whereas PD-1 had a broad expression both $\mathrm{CD} 8+$ and $\mathrm{CD} 4+\mathrm{T}$ cell population, other inhibitory molecules, like TIM-3, CTLA-4, and 4-1BB (CD137) were expressed only by a few PD-1+ subsets, indicating that a pre-exhaustion status is also present in ccRCC (108). Interestingly, both in CD8+ and CD4+ T cells, PD-1 is coexpressed with $\mathrm{CD} 38$, which mediates immunosuppression by activating nitric oxide synthetase which in turn catalyzes the production of nitric oxide from arginine. Although CD38 has traditionally been linked to $\mathrm{T}$ cell activation, these data suggest that its expression is not restricted to activated cells, but rather can be extended to exhausted T cells, at least in ccRCC and BC $(108,110)$. In the latter, a higher frequency of PD- ${ }^{\text {high }}$ CTLA$4+\mathrm{CD} 38+\mathrm{T}$ cells has been observed in tumor biopsies if compared to juxta-tumoral tissues, thus confirming that PD-1 and CD38 are both expressed in exhausted cells (110). Indeed, CD8+ T cells expressing high level of PD-1 also expressed the co-inhibitory molecules TIM-3 and CTLA- 4 , and the activation markers HLA-DR and CD38, which were not expressed by CD8+ $\mathrm{T}$ cells expressing intermediate levels of PD-1 (110). Similarly, HCC biopsies were mostly enriched by exhausted CD8+ T cells and Treg cells, and exhausted CD8 $+\mathrm{T}$ cells were increased in patients with late stage HCC if compared with early stage HCC (111).

Another cluster of special interest in HCC consisted of mucosal-associated invariant T (MAIT) cells, which are mainly involved in the protection against bacterial or viral mucosal infections (119). Although MAIT cells are considered as a first line defense in the liver, their role in liver cancer is still totally unexplored. Recent evidences revealed that tumor initiation and metastasis formation is reduced in mice knockout for MHC class I-related protein-1 (MR1), which is essential for MAIT development (120). A fraction of MAIT cells among tumor CD8+ T cells has been found also in NSCLC and CRC (109, 121). Interestingly, at least in chronic infections, MAIT cells can express inhibitory receptors, including PD-1, thus meaning that they could also be targets of ICI (122).

In uveal melanoma, single-cell analysis revealed that tumorinfiltrating immune cells, including CD8 + T cells and NK cells, mainly express LAG3, rather than PD-1 or CTLA-4 (123), thus partially explaining the limited efficacy of checkpoint inhibitor therapy in this type of tumors (124). This further confirms that PD-1 is not the exclusive determinant of CD8+ T exhaustion and that the expression of additional markers should be considered across different tumors. The situation is even further complicated by the fact that $\mathrm{T}$ cell exhaustion is associated with vast changes in chromatin accessibility (125). Emerging evidence revealed that exhausted $\mathrm{CD} 8+\mathrm{T}$ cells are epigenetically distinct from functional memory CD8 $+\mathrm{T}$ cells, thus suggesting that exhausted $\mathrm{T}$ cells occupy a different differentiation state if compared to memory T cells (125).

ScRNA-seq analysis of NK cells obtained from human melanoma metastases indicated that seven clusters of tumorinfiltrating NK are present in these tissues, each with an individual functional specialization (126). NK cells were recently shown to recruit cross-presenting DCs to tumors that are critical for CD8+ T cell-mediated tumor immunity (126).

Although $\mathrm{T}$ cells have a dominant role in controlling cancer growth, there is growing interest for other subsets of immune elements that infiltrate the TME, including B and myeloid cells, and that could have a role in the response to therapy. Tumor-infiltrating myeloid cells (TIMs) consist of various subsets of granulocytes, monocytes, macrophages and DCs, at different stage of differentiation, that contribute to cancer progression and response to therapy $(127,128)$. Among 
TIMs, the frequency of a specific subset of monocytes, i.e., CD14+, CD16-, HLA-DR ${ }^{\text {high }}$ monocytes, has been identified as predictor of progression-free and overall survival in patients with metastatic melanoma prior anti-PD-1 therapy (129). Highdimensional single-cell profiling of lung cancer revealed that an enrichment of macrophages expressing high levels of peroxisome proliferator-activated receptor (PPAR) $-\gamma$ has been observed in lung adenocarcinoma at early stage (130). Macrophages in the TME have also been studied in breast cancer, renal cancer and HCC using scRNA-seq data $(4,108,131)$. TAM-like macrophages in HCC highly express two genes, SLC40A1 and GPNMB. The former encodes ferroportin, a transporter exporting iron from cells, and regulates pro-inflammatory cytokines, like IL-6, IL23 , and IL-1 $\beta$, through a Toll like receptor (TLR)-dependent pathway (131).

Single-cell profiling of tumor biopsies also revealed that DCs can be present at the TME $(4,108,130)$. Among TIMs, DCs are the best armed to prime and activate T cells (132), and among DCs, several subsets with a specific molecular signature have been found to be depleted or enriched in the TME. This was possible by combining CyTOF with single-cell transcriptomics. For example, CD141+ DCs express high levels of CD207, CLEC9A, and $X C R 1$ and preferentially interact with CD8 $+\mathrm{T}$ cells, whereas CD1c+ DCs express high levels of CX3CR1, IRF4, CCL22, and $C C L 17$, which are involved in chemokine signaling, and are better equipped to interact with CD4+ T cells (130). Also LAMP3+ DCs have various interesting features (131). They indeed exhibit a higher migration capacity toward lymph node if compared to conventional DCs (131).

\section{Checkpoint Inhibitor Therapy Effects on TILs and PBMCs}

During the last years, single cell technologies have been used to interrogate a number of tumoral settings with the goal to understand both successful and ineffective immune responses after treatment with ICI, and identify accessible biomarkers that clinicians could use to discriminate between patients who most likely respond or not to therapy (2). The most important studies reporting the use of cutting-edge single-cell technologies to identify the effects of checkpoint inhibitor therapy on immune system are reported in Table 2 . Concerning the type of neoplasia, the vast majority of studies regard patients with melanoma or NSCLC, treated with anti-CTLA-4 or anti-PD-1 or, in few cases, with both of them.

\section{CD8+ T Cells}

Overall, among immune cells, main differences have been found in $\mathrm{T}$ cell compartment, and among $\mathrm{T}$ lymphocytes, cytotoxic cells are often affected by checkpoint inhibitor therapy. Singlecell technologies have shown that cytotoxic $\mathrm{T}$ cells do not form a homogenous population but are a heterogenous mix of cells with different transcriptomes, phenotype and functional capacity. According to their differentiation state and on the basis of the expression levels of few proteins, CD8 + T cells have been typically classified in well-defined subsets of naïve, memory, and effector cells (148). During the last few years, high-dimensional single-cell profiling allowed immunologists to understand that a variety of other states with significant phenotypic and functional diversity is observed within the CD8 + T cell compartment (149). This heterogeneity becomes increasingly relevant at the level of the TME, both within and among patients, and could be at the basis of the mechanisms linking $\mathrm{T}$ cells states and response to checkpoint inhibitor therapy.

A study performed on freshly isolated metastatic melanoma samples from two cohorts of 20 patients used flow cytometry alone to show that an increased fraction of tumor-infiltrating CD8 + T cells expressing high level of PD-1 and CTLA-4 strongly correlated with response to therapy and progression-free survival (133). These cells were named as "partially exhausted," as they retained the capacity to produce IFN-y but lose the ability to produce TNF- $\alpha$ and IL-2 (133). In another cohort of patients with melanoma treated with ICI, single-cell RNA profiling of immune cells from baseline, on-therapy and post-therapy tumor samples was performed (139). Exhausted cells were defined as those with increased expression of several genes encoding for inhibitory receptors, including LAG3, FASLG, HAVCR2 (which encodes for TIM-3), PDCD1 (which encodes for PD-1), CD38 (139). It was also showed that TIM-3 and CD39 were markers for discriminating exhausted from memory CD8+ T cells, and that the elevated frequency of TCF7,$+ \mathrm{CD} 8+\mathrm{T}$ cells can predict with a positive outcome (139). Concerning CD39, it was also found that CD8+ TILs from lung cancer and CRC were not only specific for tumor antigens but also could recognize a broad range of epitopes unrelated to cancer, and that CD39 was critical to distinguish tumor-specific CD8+ TILs from bystander CD8+ T cells (150).

In other melanoma patients treated with anti-PD-1, the combination of scRNA-seq to TCR-seq allowed to identify a dysfunctional axis consisting of cells able to actively proliferate despite having an "exhausted" phenotype (144). The application of different single-cell technologies to three different cohorts of melanoma patients treated with anti-PD-1 allowed to understand that a noteworthy phenotypic heterogeneity is observed within CD8+ TILs that display characteristics of dysfunction, reflected by various combinations and expression levels of inhibitory receptor and activation markers, the proliferative capacity and the ability to produce cytokines and effector molecules. A resistance program that is associated with hallmarks of $\mathrm{T}$ cell exclusion and suppression has also been found in malignant cells prior to immunotherapy, likely indicating the presence of intrinsic resistance (137).

Other striking results of single-cell technologies have been obtained in blood samples from cancer patients treated with ICI. In those with melanoma, circulating Ki67+, CD8+ T cell response was correlated with tumor burden (134). Similar results were found in NSCLC treated with anti-PD-1. After therapy, an increase of $\mathrm{Ki}-67+, \mathrm{PD}-1+$, CD8 + T cells displaying an effectorlike phenotype (HLA-DR+, CD38+, Bcl-2 low $)$, costimulatory molecules (CD28+, CD27+, ICOS + ), high levels of PD-1 and co-expression of CTLA-4 was observed in patients responding to therapy $(135,140)$. In the same patients, the expansion of CD39+, CD8+ T cells was observed a few days after a single dose of anti-PD-1 in a neoadjuvant setting (145). Tracking TCR clones and transcriptional phenotypes in basal cell carcinoma (BCC) 
TABLE 2 | Main studies reporting the use of cutting-edge single-cell technologies to identify the effects of checkpoint inhibitor therapy on immune system.

\begin{tabular}{|c|c|c|c|c|}
\hline Tumor type & $\begin{array}{l}\text { Sample } \\
\text { source }\end{array}$ & Technology & Main findings & References \\
\hline Melanoma & TILs & Flow cytometry & $\begin{array}{l}\text { - High level of CD8+, PD- } 1^{++}, \text {CTLA-4++ TILs correlated with } \\
\text { response to therapy and progression-free survival; } \\
\text { - Functional analysis of these cells revealed a partially exhausted } \\
\text { T cell phenotype; } \\
\text { - Assessment of metastatic lesions during anti-PD-1 therapy } \\
\text { demonstrated a release of T cell exhaustion, as measured by an } \\
\text { accumulation of highly activated CD8+ T cells within tumors. }\end{array}$ & $(133)$ \\
\hline Melanoma & $\begin{array}{l}\text { PBMCs } \\
\text { TILs }\end{array}$ & Flow cytometry & $\begin{array}{l}\text { - CD8+ T cells responding to therapy display an } \\
\text { exhausted phenotype; } \\
\text { - TIL clones in responding peripheral blood CD8+ T cell } \\
\text { population and blood Ki67+, CD8+ T cell response correlates } \\
\text { with tumor burden. }\end{array}$ & (134) \\
\hline NSCLC & PBMCs & Flow cytometry & $\begin{array}{l}\text { - Increase in Ki67+, PD-1+, CD8+ T cells following therapy in } \\
\sim 70 \% \text { of patients (after the first or second treatment cycle); } \\
\text { - Effector-like phenotype (HLA-DR+, CD38+, Bcl-2 }{ }^{\text {low }} \text { ), } \\
\text { expressed costimulatory molecules (CD28, CD27, ICOS), and } \\
\text { had high levels of PD-1 and coexpression of CTLA-4. }\end{array}$ & (135) \\
\hline Melanoma & TILs & $\begin{array}{l}\text { Mass cytometry; } \\
\text { RNA-seq }\end{array}$ & $\begin{array}{l}\text { - The CD8+ T cell population expanded in ICl-treated tumors } \\
\text { displayed a CD45R0+, PD-1+, TBET+, EOMES+ phenotype; } \\
\text { - CTLA-4 blockade induces expansion of ICOS+ Th1-like CD4+ } \\
\text { T cells. }\end{array}$ & $(136)$ \\
\hline Melanoma & tumor & $\begin{array}{l}\text { RNA-seq; } \\
\text { scRNA-seq; } \\
\text { in situ multiplex } \\
\text { protein }\end{array}$ & $\begin{array}{l}\text { - Resistance program expressed by malignant cells, associated } \\
\text { with T cell exclusion and immune evasion. The program is } \\
\text { expressed prior to immunotherapy, characterizes cold niches in } \\
\text { situ, and predicts clinical responses therapy; } \\
\text { - CDK4/6-inhibition represses this program in individual malignant } \\
\text { cells, induces senescence, and reduces melanoma tumor } \\
\text { outgrowth in mouse models in vivo when given in combination } \\
\text { with immunotherapy. }\end{array}$ & $(137)$ \\
\hline NSCLC & TILs & $\begin{array}{l}\text { Flow cytometry } \\
\text { RNA-seq }\end{array}$ & $\begin{array}{l}\text { - PD-1++ T cells showed a markedly different transcriptional and } \\
\text { metabolic profile from PD-1+- and PD-1- lymphocytes, as well } \\
\text { as an intrinsically high capacity for tumor recognition; } \\
\text { - PD-1 } 1^{++} \text {Iymphocytes were impaired in classical effector } \\
\text { cytokine production, they produced CXCL13, which mediates } \\
\text { immune cell recruitment to tertiary lymphoid structures; } \\
\text { - The presence of PD-1 } 1^{++} \text {cells was strongly predictive for both } \\
\text { response and survival. }\end{array}$ & (138) \\
\hline Melanoma & tumor & $\begin{array}{l}\text { scRNA-seq; } \\
\text { ATAC-seq }\end{array}$ & $\begin{array}{l}\text { - Two distinct states of CD8+ T cells were defined by clustering } \\
\text { and associated with patient tumor regression or progression; } \\
\text { - TCF7 was visualized within CD8+ T cells in fixed tumor samples } \\
\text { and predicted positive clinical outcome. }\end{array}$ & (139) \\
\hline $\begin{array}{l}\text { Melanoma } 1 \\
\text { patient, } 90 \text { years } \\
\text { old }\end{array}$ & PBMCs TILs & $\begin{array}{l}\text { Flow cytometry; } \\
\text { TCR sequencing }\end{array}$ & $\begin{array}{l}\text { - Proliferating CD8+ T cells exhibited an effector-like phenotype } \\
\text { with expression of CD38, HLA-DR and Granzyme B, as well as } \\
\text { expression of the positive costimulatory molecules CD28 } \\
\text { and CD27; } \\
\text { - TCR sequencing of peripheral blood CD8+ T cells revealed a } \\
\text { highly oligoclonal repertoire at baseline with one clonotype } \\
\text { accounting for } 30 \% \text {. }\end{array}$ & $(140)$ \\
\hline Melanoma & PBMCs & Mass cytometry & $\begin{array}{l}\text { - Frequency of CD14+, CD16-, HLA-DR }{ }^{\text {hi }} \text { monocytes before } \\
\text { therapy is a strong predictor of progression-free and } \\
\text { overall survival. }\end{array}$ & (129) \\
\hline $\begin{array}{l}\text { Melanoma, } \\
\text { NSCLC }\end{array}$ & TILs PBMCs & $\begin{array}{l}\text { Flow cytometry; } \\
\text { RNA-seq }\end{array}$ & $\begin{array}{l}\text { - } \text { CD4+, FoxP3-, PD-1 }{ }^{\text {hi }} \text { T cells (4PD1 } 1^{\text {hi }} \text {, a TFH-like phenotype) } \\
\text { negatively regulate T cell responses; } \\
\text { - } \text { CTLA-4 and PD-1 blockade modulate 4PD1 }{ }^{\text {hi }} \text { frequency in } \\
\text { opposing directions; } \\
\text { - } 4 \text { PD1 }{ }^{\text {hi }} \text { are a pharmacodynamic and negative prognostic factor } \\
\text { of checkpoint blockade. }\end{array}$ & $(141)$ \\
\hline $\begin{array}{l}\text { Melanoma, } \\
\text { Prostate cancer, } \\
\text { Bladder cancer }\end{array}$ & Tumor & IHC; CyTOF & $\begin{array}{l}\text { - Both ipilimumab and tremelimumab increase the infiltration of } \\
\text { CD4+ and CD8+ cells without significantly changing or } \\
\text { depleting FOXP3 cells within the tumor microenvironment. }\end{array}$ & $(42)$ \\
\hline
\end{tabular}


TABLE 2 | Continued

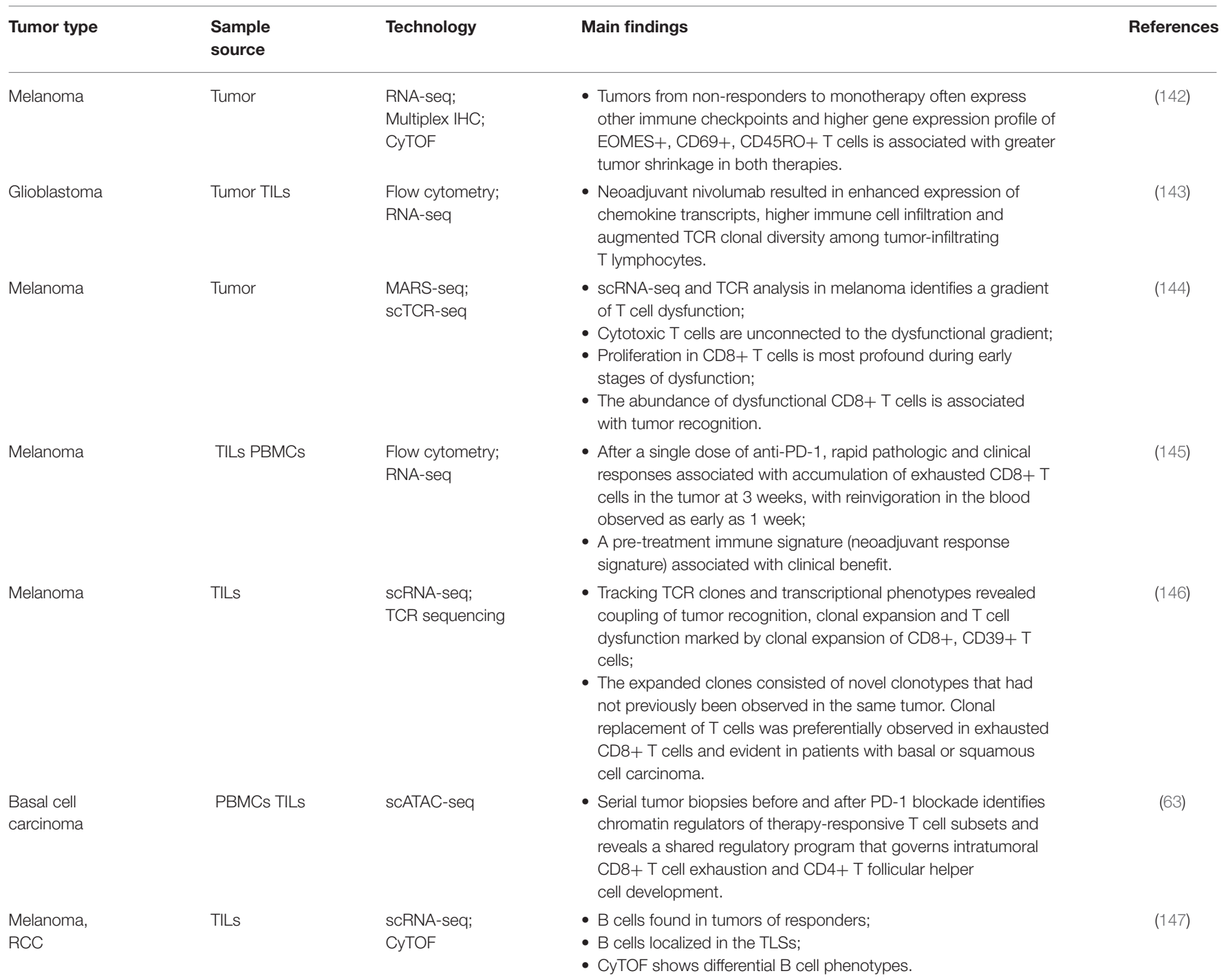

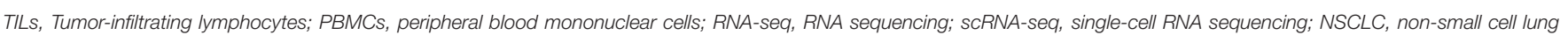

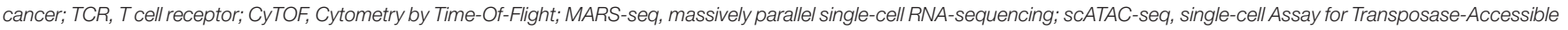
Chromatin using sequencing; ICI, immune checkpoint inhibitors; TLSs, tertiary lymphoid structures; IHC, immunohistochemistry.

also revealed clonal expansion of $\mathrm{CD} 8+, \mathrm{CD} 39+\mathrm{T}$ cells, which co-expressed markers of chronic $\mathrm{T}$ cell activation and exhaustion. However, in this case, the expansion of $\mathrm{T}$ cell clones did not derive from pre-existing TILs, but from novel clonotypes that had not previously been observed in the same tumor (146). This suggests that the response to anti-PD-1 depends on the intrinsic capacity of tumors to recruit novel $\mathrm{T}$ cell clones, which replace pre-existing exhausted $\mathrm{T}$ cells that have insufficient capacity to reinvigorate in response to therapy (151).

In addition, data obtained from melanoma samples and peripheral blood from patients treated with anti-CTLA-4 and anti-PD-1 revealed that treatment-specific effects can be observed. Indeed, while anti-PD-1 mainly induced the expansion of specific tumor-infiltrating exhausted-like CD8+ T cell subsets, anti-CTLA-4 led to the expansion of an ICOS+ Th1-like
CD4+ effector subsets other than engaging specific subsets of exhausted-like CD8 T cells (136). It was also reported that the population of $\mathrm{CD} 8+, \mathrm{CD} 45 \mathrm{RO}+, \mathrm{PD}-1+, \mathrm{TBET}+, \mathrm{EOMES}+\mathrm{T}$ cells increased after treatment only in TILs if compared to the peripheral blood (136), and that the gene expression signature of EOMES+, CD69+, CD45RO+ T cells was associated with greater tumor shrinkage in both therapies (142). Likewise, in a cohort of patients with NSCLC treated with anti-PD1 , the presence of $\mathrm{PD}-1^{++} \mathrm{T}$ cells within the tumor was strongly predictive for both response and survival (138). PD$1^{++} \mathrm{T}$ cells indeed produce C-X-C Motif Chemokine Ligand 13 (CXCL13), which mediates immune cell recruitment to TLSs (138). Similarly, in a cohort of patients with GMB treated with anti-PD-1 an enhanced expression of chemokine transcripts, higher immune cell infiltration and augmented TCR clonal 
diversity among tumor-infiltrating TILs was reported (143). In summary, a large variability can be observed among different patients' cohorts concerning the abundance of different $\mathrm{T}$ cell functional states. An increase in CD8+ T cells with an effectorlike phenotype expressing inhibitory/costimulatory molecules and proliferations markers has been described in several cancer settings after therapy with ICI. However, only in few cases this immune cellular response were correlated with a measurable clinical response.

\section{CD4+ T Cells}

The vast majority of recent studies based on single-cell technologies have been focused on CD8 $+\mathrm{T}$ cells, as their role in cancer surveillance, editing and control is compelling. However, a role in tumor control is also played by the CD4+ $\mathrm{T}$ cell compartment, as reflected by the observation that $\mathrm{CD} 4+\mathrm{T}$ cells infiltrate the tumor, and by the prognostic value of several CD4 subsets in different malignancies (152-154). Distinct CD4+ $\mathrm{T}$ cells subsets have been described by means of single-cell technologies, including naïve cells, memory-like cells, Th1 cells, Treg, follicular helper $\mathrm{T}$ cells $\left(\mathrm{T}_{\mathrm{FH}}\right)$, and even cytotoxic effector $\mathrm{T}$ cells $(109,111,121,141,144,146,155,156)$.

In NSCLC tumor and blood samples, scRNA-seq allowed to identify seven CD4+ T cell populations (109). Interestingly, among them an "exhausted" CD4+ T subset was present and displayed a gene signature comparable to that observed in exhausted CD8+ T cells. Two Treg clusters were also identified and one of them was defined as "suppressive Treg" as cells expressed high levels of TNFRSF9 (encoding for 4-IBB), TIGIT and CTLA-4 genes (109). A closer quantification of this cluster in blood and tumor samples revealed that a higher percentage of suppressive Treg cells was present in tumor if compared to blood (109).

A combination of scRNA-seq and TCR analysis allowed to identify a subset of "dysfunctional" CD4+ T cells in a cohort of melanoma patients, and again these dysfunctional cells expressed specific combinations of genes encoding for inhibitory checkpoints that partially overlapped with those observed in CD8+ $\mathrm{T}$ cells (144). The fact that in TME CD4+ T cell also express PD-1 and/or CTLA-4 suggests that most of the current immunotherapy strategies that use checkpoint inhibitor can potentially leverage on these cells. Although data dissecting the effects of these drugs on $\mathrm{CD} 4+\mathrm{T}$ cells are still elusive, it was recently found that in melanoma patients treated with anti-PD-1/anti-CTLA4 the frequency of the $\mathrm{T}$ cell population characterized by a $\mathrm{T}_{\mathrm{FH}}$-like phenotype $(\mathrm{CD} 4+$, Foxp3-, $\mathrm{PD}$ $\left.1^{\text {high }}\right)$ is modulated differently by the two drugs and is a negative prognostic factor of response to therapy (141).

\section{Other Cells Than T Lymphocytes}

Through mass cytometry and scRNA-seq, in GMB a unique subset of macrophages expressing high levels of CD73 able to persist after anti-PD-1 therapy was observed (88). Notably, a number of reports have shown that CD73 can induce immunosuppression in GMB $(157,158)$.

Tumor-infiltrating $\mathrm{B}$ cells exist and are mainly found in lymphoid aggregates, known as TLSs $(147,159)$. It was found that the density of CD20+ B cells and TLSs, together with the ratio of TLSs to tumor area were higher in responders than in non-responders (147). Moreover, a prognostic B-cell-related gene signature was found in patients with cutaneous melanoma or RCC. Several genes, including FCRL5, IDO1, IFNG, and BTLA, were indeed enriched in patients responding to therapy (147).

\section{CONCLUSIONS}

The interactions between tumor and immune system are ruled by several complex mechanisms, with several main players such as malignant cells, tumor infiltrate, tumor stroma and vasculature, and systemic factors. Among them, the heterogeneity of intratumor immune cells has been extensively studied by using traditional approaches, including basic flow cytometry and immunohistochemistry, which have the limitations described above. Recently, substantial advances in emerging techniques and bioinformatic pipelines have enabled researchers to investigate in detail the complexity of the TME, and to interrogate in depth previously unexplored cell types. Among single-cell approaches, scRNA-seq has been crucial for exploratory analysis, and the combination of scRNA-seq with mass cytometry has been even more helpful.

The application of single-cell technologies to tumor and blood samples has generated and will generate in the upcoming years, an explosion of new data with a clear impact in the translational clinical research, thanks to the identification of possible biomarkers. It is likely that the huge amount of information will also thoroughly revolutionize the field of basic research in immunology and cancer biology. A big effort should be posed to make all data, including the raw ones, available to the scientific community and to create rigs for data extraction. The information gathered from these technologies will add novel hallmarks of response to immune therapy that could be integrated in the routine clinical management.

Nonetheless, the route to the discovery of new biomarkers is still bumpy. Due to the high sensitivity of single-cell technologies, adequate attention must be put into experimental setup and execution. A very careful handling of cells during pre-processing and an adequate data analysis with potent bioinformatic tools are critical factors to preserve the native biological profile that will ensure meaningful conclusions.

Lastly but importantly, although a number of specific immune cell subsets have been identified that are associated with response or resistance to ICI, still additional studies should be planned to address the role and function of different types of immune cells in the TME. Investigating the role of $\mathrm{T}$ cell exhaustion and/or dysfunction in the TME and translating this knowledge to clinical practice can be considered main challenges in the battle against cancer.

\section{AUTHOR CONTRIBUTIONS}

$\mathrm{CP}, \mathrm{RD}, \mathrm{GP}, \mathrm{RS}$, and AC outlined the concept, wrote the manuscript, and overviewed the review. LG and SD wrote the manuscript. LG, SD, and DL designed and prepared the figures. 


\section{FUNDING}

This study was supported by a grant to AC and GP by Fondazione Cassa di Risparmio di Modena e Reggio Emilia, and by the grant Fondo di Ateneo per la Ricerca (FAR) 2017 to AC.

\section{REFERENCES}

1. Wilky BA. Immune checkpoint inhibitors: the linchpins of modern immunotherapy. Immunol Rev. (2019) 290:6-23. doi: 10.1111/imr. 12766

2. Havel JJ, Chowell D, Chan TA. The evolving landscape of biomarkers for checkpoint inhibitor immunotherapy. Nat Rev Cancer. (2019) 19:133-50. doi: 10.1038/s41568-019-0116-x

3. McGranahan N, Furness AJ, Rosenthal R, Ramskov S, Lyngaa R, Saini SK, et al. Clonal neoantigens elicit $\mathrm{T}$ cell immunoreactivity and sensitivity to immune checkpoint blockade. Science. (2016) 351:1463-9. doi: 10.1126/science.aaf1490

4. Azizi E, Carr AJ, Plitas G, Cornish AE, Konopacki C, Prabhakaran $\mathrm{S}$, et al. Single-cell map of diverse immune phenotypes in the breast tumor microenvironment. Cell. (2018) 174:1293-308.e36. doi: 10.1016/j.cell.2018.05.060

5. Flavell RA, Sanjabi S, Wrzesinski SH, Licona-Limon P. The polarization of immune cells in the tumour environment by TGFbeta. Nat Rev Immunol. (2010) 10:554-67. doi: 10.1038/nri2808

6. Jenkins RW, Barbie DA, Flaherty KT. Mechanisms of resistance to immune checkpoint inhibitors. Br J Cancer. (2018) 118:9-16. doi: 10.1038/bjc.2017.434

7. Hanahan D, Weinberg RA. Hallmarks of cancer: the next generation. Cell. (2011) 144:646-74. doi: 10.1016/j.cell.2011.02.013

8. Dighe AS, Richards E, Old LJ, Schreiber RD. Enhanced in vivo growth and resistance to rejection of tumor cells expressing dominant negative IFN gamma receptors. Immunity. (1994) 1:447-56. doi: 10.1016/1074-7613(94)90087-6

9. Girardi M, Oppenheim DE, Steele CR, Lewis JM, Glusac E, Filler R, et al. Regulation of cutaneous malignancy by gammadelta T cells. Science. (2001) 294:605-9. doi: 10.1126/science.1063916

10. Kaplan DH, Shankaran V, Dighe AS, Stockert E, Aguet M, Old LJ, et al. Demonstration of an interferon gamma-dependent tumor surveillance system in immunocompetent mice. Proc Natl Acad Sci USA. (1998) 95:755661. doi: 10.1073/pnas.95.13.7556

11. Shankaran V, Ikeda H, Bruce AT, White JM, Swanson PE, Old LJ, et al. IFNgamma and lymphocytes prevent primary tumour development and shape tumour immunogenicity. Nature. (2001) 410:1107-11. doi: $10.1038 / 35074122$

12. Smyth MJ, Thia KY, Street SE, Cretney E, Trapani JA, Taniguchi M, et al. Differential tumor surveillance by natural killer (NK) and NKT cells. J Exp Med. (2000) 191:661-8. doi: 10.1084/jem.191.4.661

13. Smyth MJ, Thia KY, Street SE, MacGregor D, Godfrey DI, Trapani JA. Perforin-mediated cytotoxicity is critical for surveillance of spontaneous lymphoma. J Exp Med. (2000) 192:755-60. doi: 10.1084/jem.192. 5.755

14. Schreiber RD, Old LJ, Smyth MJ. Cancer immunoediting: integrating immunity's roles in cancer suppression and promotion. Science. (2011) 331:1565-70. doi: 10.1126/science. 1203486

15. Engel AM, Svane IM, Rygaard J, Werdelin O. MCA sarcomas induced in scid mice are more immunogenic than MCA sarcomas induced in congenic, immunocompetent mice. Scand J Immunol. (1997) 45:463-70. doi: 10.1046/j.1365-3083.1997.d01-419.x

16. Smyth MJ, Crowe NY, Godfrey DI. NK cells and NKT cells collaborate in host protection from methylcholanthrene-induced fibrosarcoma. Int Immunol. (2001) 13:459-63. doi: 10.1093/intimm/13.4.459

17. Krelin Y, Voronov E, Dotan S, Elkabets M, Reich E, Fogel $\mathrm{M}$, et al. Interleukin-1beta-driven inflammation promotes the development and invasiveness of chemical carcinogen-induced tumors.

\section{ACKNOWLEDGMENTS}

$\mathrm{SD}$ is a Marylou Ingram Scholar of the International Society for Advancement of Cytometry (ISAC).

Cancer Res. (2007) 67:1062-71. doi: 10.1158/0008-5472.CAN-062956

18. Liu J, Xiang Z, Ma X. Role of IFN regulatory factor-1 and IL-12 in immunological resistance to pathogenesis of N-methyl-Nnitrosourea-induced T lymphoma. J Immunol. (2004) 173:1184-93. doi: 10.4049/jimmunol.173.2.1184

19. Street SE, Cretney E, Smyth MJ. Perforin and interferon-gamma activities independently control tumor initiation, growth, and metastasis. Blood. (2001) 97:192-7. doi: 10.1182/blood.V97. 1.192

20. Swann JB, Vesely MD, Silva A, Sharkey J, Akira S, Schreiber RD, et al. Demonstration of inflammation-induced cancer and cancer immunoediting during primary tumorigenesis. Proc Natl Acad Sci USA. (2008) 105:652-6. doi: 10.1073/pnas.0708594105

21. Boshoff C, Weiss R. AIDS-related malignancies. Nat Rev Cancer. (2002) 2:373-82. doi: 10.1038/nrc797

22. Buell JF, Gross TG, Woodle ES. Malignancy after transplantation. Transplantation. (2005) 80(2 Suppl):S254-64. doi: 10.1097/01.tp.0000186382.81130.ba

23. Moloney FJ, Comber H, O’Lorcain P, O'Kelly P, Conlon PJ, Murphy GM. A population-based study of skin cancer incidence and prevalence in renal transplant recipients. Br J Dermatol. (2006) 154:498-504. doi: 10.1111/j.1365-2133.2005.07021.x

24. Aberg F, Pukkala E, Hockerstedt K, Sankila R, Isoniemi H. Risk of malignant neoplasms after liver transplantation: a population-based study. Liver Transpl. (2008) 14:1428-36. doi: 10.1002/lt.21475

25. Baccarani U, Piselli P, Serraino D, Adani GL, Lorenzin D, Gambato M, et al. Comparison of de novo tumours after liver transplantation with incidence rates from Italian cancer registries. Dig Liver Dis. (2010) 42:55-60. doi: 10.1016/j.dld.2009.04.017

26. Vesely MD, Kershaw MH, Schreiber RD, Smyth MJ. Natural innate and adaptive immunity to cancer. Annu Rev Immunol. (2011) 29:235-71. doi: 10.1146/annurev-immunol-031210-101324

27. Swann JB, Smyth MJ. Immune surveillance of tumors. J Clin Invest. (2007) 117:1137-46. doi: 10.1172/JCI31405

28. Pardoll D. Cancer and the immune system: basic concepts and targets for intervention. Semin Oncol. (2015) 42:523-38. doi: 10.1053/j.seminoncol.2015.05.003

29. Virchow R. Die krankhaften Geschwulste. Berlin: Verlag August Hirschwald Berlin (1863-1865).

30. Clark WH Jr, Elder DE, Guerry DT, Braitman LE, Trock BJ, Schultz D, et al. Model predicting survival in stage I melanoma based on tumor progression. J Natl Cancer Inst. (1989) 81:1893-904. doi: 10.1093/jnci/81. 24.1893

31. Clemente CG, Mihm MC Jr, Bufalino R, Zurrida S, Collini P, Cascinelli N, et al. Prognostic value of tumor infiltrating lymphocytes in the vertical growth phase of primary cutaneous melanoma. Cancer. (1996) 77:1303-10. doi: 10. 1002/(SICI)1097-0142(19960401)77:7<1303::AID-CNCR12>3.0.CO;2-5

32. Galon J, Costes A, Sanchez-Cabo F, Kirilovsky A, Mlecnik B, LagorcePages C, et al. Type, density, and location of immune cells within human colorectal tumors predict clinical outcome. Science. (2006) 313:1960-4. doi: 10.1126/science.1129139

33. Pages F, Berger A, Camus M, Sanchez-Cabo F, Costes A, Molidor $\mathrm{R}$, et al. Effector memory $\mathrm{T}$ cells, early metastasis, and survival in colorectal cancer. N Engl J Med. (2005) 353:2654-66. doi: 10.1056/NEJMoa0 51424

34. Sato E, Olson SH, Ahn J, Bundy B, Nishikawa H, Qian F, et al. Intraepithelial $\mathrm{CD} 8+$ tumor-infiltrating lymphocytes and a high CD8+/regulatory $\mathrm{T}$ cell ratio are associated with favorable prognosis in ovarian cancer. 
Proc Natl Acad Sci USA. (2005) 102:18538-43. doi: 10.1073/pnas.05091 82102

35. van Houdt IS, Sluijter BJ, Moesbergen LM, Vos WM, de Gruijl TD, Molenkamp BG, et al. Favorable outcome in clinically stage II melanoma patients is associated with the presence of activated tumor infiltrating Tlymphocytes and preserved MHC class I antigen expression. Int J Cancer. (2008) 123:609-15. doi: 10.1002/ijc.23543

36. Zhang L, Conejo-Garcia JR, Katsaros D, Gimotty PA, Massobrio M, Regnani $\mathrm{G}$, et al. Intratumoral T cells, recurrence, and survival in epithelial ovarian cancer. N Engl J Med. (2003) 348:203-13. doi: 10.1056/NEJMoa020177

37. Binnewies M, Roberts EW, Kersten K, Chan V, Fearon DF, Merad M, et al. Understanding the tumor immune microenvironment (TIME) for effective therapy. Nat Med. (2018) 24:541-50. doi: 10.1038/s41591-018-0014-x

38. Sautes-Fridman C, Petitprez F, Calderaro J, Fridman WH. Tertiary lymphoid structures in the era of cancer immunotherapy. Nat Rev Cancer. (2019) 19:307-25. doi: 10.1038/s41568-019$0144-6$

39. Rowshanravan B, Halliday N, Sansom DM. CTLA-4: a moving target in immunotherapy. Blood. (2018) 131:58-67. doi: 10.1182/blood-2017-06-741033

40. Pol J, Kroemer G. Anti-CTLA-4 immunotherapy: uncoupling toxicity and efficacy. Cell Res. (2018) 28:501-2. doi: 10.1038/s41422-018-0031-9

41. Selby MJ, Engelhardt JJ, Quigley M, Henning KA, Chen T, Srinivasan M, et al. Anti-CTLA-4 antibodies of IgG2a isotype enhance antitumor activity through reduction of intratumoral regulatory T cells. Cancer Immunol Res. (2013) 1:32-42. doi: 10.1158/2326-6066.CIR-13-0013

42. Sharma A, Subudhi SK, Blando J, Vence L, Wargo J, Allison JP, et al. Anti-CTLA-4 immunotherapy does not deplete FOXP3+ regulatory T cells (Tregs) in human cancers-response. Clin Cancer Res. (2019) 25:3469-70. doi: 10.1158/1078-0432.CCR-19-0402

43. Hodi FS, O'Day SJ, McDermott DF, Weber RW, Sosman JA, Haanen JB, et al. Improved survival with ipilimumab in patients with metastatic melanoma. $N$ Engl J Med. (2010) 363:711-23. doi: 10.1056/NEJMoa1003466

44. Robert C, Thomas L, Bondarenko I, O’Day S, Weber J, Garbe C, et al. Ipilimumab plus dacarbazine for previously untreated metastatic melanoma. N Engl J Med. (2011) 364:2517-26. doi: 10.1056/NEJMoa1104621

45. Thommen DS, Schumacher TN. T cell dysfunction in cancer. Cancer Cell. (2018) 33:547-62. doi: 10.1016/j.ccell.2018.03.012

46. Wu Y, Chen W, Xu ZP, Gu W. PD-L1 distribution and perspective for cancer immunotherapy-blockade, knockdown, or inhibition. Front Immunol. (2019) 10:2022. doi: 10.3389/fimmu.2019.02022

47. Gong J, Chehrazi-Raffle A, Reddi S, Salgia R. Development of PD-1 and PDL1 inhibitors as a form of cancer immunotherapy: a comprehensive review of registration trials and future considerations. J Immunother Cancer. (2018) 6:8. doi: 10.1186/s40425-018-0316-z

48. Wolchok JD, Chiarion-Sileni V, Gonzalez R, Rutkowski P, Grob JJ, Cowey CL, et al. Overall survival with combined nivolumab and ipilimumab in advanced melanoma. N Engl J Med. (2017) 377:1345-56. doi: 10.1056/NEJMoa1709684

49. Hodi FS, Chiarion-Sileni V, Gonzalez R, Grob JJ, Rutkowski P, Cowey CL, et al. Nivolumab plus ipilimumab or nivolumab alone versus ipilimumab alone in advanced melanoma (CheckMate 067): 4-year outcomes of a multicentre, randomised, phase 3 trial. Lancet Oncol. (2018) 19:1480-92. doi: 10.1016/S1470-2045(18)30700-9

50. Motzer RJ, Penkov K, Haanen J, Rini B, Albiges L, Campbell MT, et al. Avelumab plus axitinib versus sunitinib for advanced renal-cell carcinoma. N Engl J Med. (2019) 380:1103-15. doi: 10.1056/NEJMoa1816047

51. Motzer RJ, Rini BI, McDermott DF, Aren Frontera O, Hammers HJ, Carducci MA, et al. Nivolumab plus ipilimumab versus sunitinib in first-line treatment for advanced renal cell carcinoma: extended follow-up of efficacy and safety results from a randomised, controlled, phase 3 trial. Lancet Oncol. (2019) 20:1370-85. doi: 10.1016/S1470-2045(19)30413-9

52. Rini BI, Powles T, Atkins MB, Escudier B, McDermott DF, Suarez C, et al. Atezolizumab plus bevacizumab versus sunitinib in patients with previously untreated metastatic renal cell carcinoma (IMmotion151): a multicentre, open-label, phase 3, randomised controlled trial. Lancet. (2019) 393:2404-15. doi: 10.1016/S0140-6736(19)30723-8
53. Gadalla R, Noamani B, MacLeod BL, Dickson RJ, Guo M, Xu W, et al. Validation of CyTOF against flow cytometry for immunological studies and monitoring of human cancer clinical trials. Front Oncol. (2019) 9:415. doi: $10.3389 /$ fonc. 2019.00415

54. Spitzer MH, Nolan GP. Mass cytometry: single cells, many features. Cell. (2016) 165:780-91. doi: 10.1016/j.cell.2016.04.019

55. Robinson JP. Comparative overview of flow and image cytometry. Curr Protoc Cytom. (2005) Chapter 12:Unit 12.1. doi: 10.1002/0471142956.cy1201s31

56. Gerner MY, Kastenmuller W, Ifrim I, Kabat J, Germain RN. Histo-cytometry: a method for highly multiplex quantitative tissue imaging analysis applied to dendritic cell subset microanatomy in lymph nodes. Immunity. (2012) 37:364-76. doi: 10.1016/j.immuni.2012.07.011

57. Chang Q, Ornatsky OI, Siddiqui I, Loboda A, Baranov VI, Hedley DW. Imaging mass cytometry. Cytometry A. (2017) 91:160-9. doi: $10.1002 /$ cyto.a. 23053

58. Baharlou H, Canete NP, Cunningham AL, Harman AN, Patrick E. Mass cytometry imaging for the study of human diseases-applications and data analysis strategies. Front Immunol. (2019) 10:2657. doi: $10.3389 /$ fimmu.2019.02657

59. Schapiro D, Jackson HW, Raghuraman S, Fischer JR, Zanotelli VRT, Schulz D, et al. histoCAT: analysis of cell phenotypes and interactions in multiplex image cytometry data. Nat Methods. (2017) 14:873-6. doi: $10.1038 /$ nmeth.4391

60. Papalexi E, Satija R. Single-cell RNA sequencing to explore immune cell heterogeneity. Nat Rev Immunol. (2018) 18:35-45. doi: 10.1038/nri.2017.76

61. Chen G, Ning B, Shi T. Single-cell RNA-seq technologies and related computational data analysis. Front Genet. (2019) 10:317. doi: 10.3389/fgene.2019.00317

62. Wang Y, Navin NE. Advances and applications of single-cell sequencing technologies. Mol Cell. (2015) 58:598-609. doi: 10.1016/j.molcel.2015.05.005

63. Satpathy AT, Granja JM, Yost KE, Qi Y, Meschi F, McDermott GP, et al. Massively parallel single-cell chromatin landscapes of human immune cell development and intratumoral T cell exhaustion. Nat Biotechnol. (2019) 37:925-36. doi: 10.1038/s41587-019-0206-z

64. Cossarizza A, Radbruch A. Cytometry for immunology: a stable and happy marriage. Cytometry A. (2013) 83:673-5. doi: 10.1002/cyto.a.22336

65. Cossarizza A, Radbruch A. Cytometry for immunology: the marriage continues. Cytometry A. (2014) 85:13-4. doi: 10.1002/cyto.a.22429

66. Chattopadhyay PK, Winters AF, Lomas WE III, Laino AS, Woods DM. High-parameter single-cell analysis. Annu Rev Anal Chem. (2019) 12:411-30. doi: 10.1146/annurev-anchem-061417-125927

67. Cossarizza A, Chang HD, Radbruch A, Acs A, Adam D, Adam-Klages $\mathrm{S}$, et al. Guidelines for the use of flow cytometry and cell sorting in immunological studies (second edition). Eur J Immunol. (2019) 49:1457-973. doi: 10.1002/eji.201970107

68. Maciorowski Z, Chattopadhyay PK, Jain P. Basic multicolor flow cytometry. Curr Protoc Immunol. (2017) 117:5.4.1-5.4.38. doi: 10.1002/cpim.26

69. Mahnke Y, Chattopadhyay P, Roederer M. Publication of optimized multicolor immunofluorescence panels. Cytometry A. (2010) 77:814-8. doi: 10.1002/cyto.a.20916

70. Mahnke YD, Roederer M. Optimizing a multicolor immunophenotyping assay. Clin Lab Med. (2007) 27:469-85. doi: 10.1016/j.cll.2007.05.002

71. Nguyen R, Perfetto S, Mahnke YD, Chattopadhyay P, Roederer M. Quantifying spillover spreading for comparing instrument performance and aiding in multicolor panel design. Cytometry A. (2013) 83:306-15. doi: 10.1002/cyto.a.22251

72. Roederer M. Compensation in flow cytometry. Curr Protoc Cytom. (2002) Chapter 1:Unit 1.14. doi: 10.1002/0471142956.cy0114s22

73. Finotello F, Rieder D, Hackl H, Trajanoski Z. Next-generation computational tools for interrogating cancer immunity. Nat Rev Genet. (2019) 20:724-46. doi: 10.1038/s41576-019-0166-7

74. Landhuis E. Single-cell approaches to immune profiling. Nature. (2018) 557:595-7. doi: 10.1038/d41586-018-05214-w

75. Goltsev Y, Samusik N, Kennedy-Darling J, Bhate S, Hale M, Vazquez G, et al. Deep profiling of mouse splenic architecture with CODEX multiplexed imaging. Cell. (2018) 174:968-81.e15. doi: 10.1016/j.cell.2018.07.010 
76. Holzwarth K, Kohler R, Philipsen L, Tokoyoda K, Ladyhina V, Wahlby $\mathrm{C}$, et al. Multiplexed fluorescence microscopy reveals heterogeneity among stromal cells in mouse bone marrow sections. Cytometry A. (2018) 93:87688. doi: 10.1002/cyto.a.23526

77. Giesen C, Wang HA, Schapiro D, Zivanovic N, Jacobs A, Hattendorf B, et al. Highly multiplexed imaging of tumor tissues with subcellular resolution by mass cytometry. Nat Methods. (2014) 11:417-22. doi: 10.1038/nmeth. 2869

78. Hwang B, Lee JH, Bang D. Single-cell RNA sequencing technologies and bioinformatics pipelines. Exp Mol Med. (2018) 50:96. doi: 10.1038/s12276-018-0071-8

79. Tang F, Barbacioru C, Wang Y, Nordman E, Lee C, Xu N, et al. mRNA-Seq whole-transcriptome analysis of a single cell. Nat Methods. (2009) 6:377-82. doi: 10.1038/nmeth.1315

80. Ramskold D, Luo S, Wang YC, Li R, Deng Q, Faridani OR, et al. Full-length mRNA-Seq from single-cell levels of RNA and individual circulating tumor cells. Nat Biotechnol. (2012) 30:777-82. doi: 10.1038/nbt.2282

81. Nikolich-Zugich J, Slifka MK, Messaoudi I. The many important facets of T-cell repertoire diversity. Nat Rev Immunol. (2004) 4:123-32. doi: $10.1038 /$ nri1292

82. De Simone M, Rossetti G, Pagani M. Single cell $\mathrm{T}$ cell receptor sequencing: techniques and future challenges. Front Immunol. (2018) 9:1638. doi: 10.3389/fimmu.2018.01638

83. Hogan SA, Courtier A, Cheng PF, Jaberg-Bentele NF, Goldinger SM, Manuel $\mathrm{M}$, et al. Peripheral blood TCR repertoire profiling may facilitate patient stratification for immunotherapy against melanoma. Cancer Immunol Res. (2019) 7:77-85. doi: 10.1158/2326-6066.CIR-18-0136

84. Tumeh PC, Harview CL, Yearley JH, Shintaku IP, Taylor EJ, Robert L, et al. PD-1 blockade induces responses by inhibiting adaptive immune resistance. Nature. (2014) 515:568-71. doi: 10.1038/nature13954

85. Peterson VM, Zhang KX, Kumar N, Wong J, Li L, Wilson DC, et al. Multiplexed quantification of proteins and transcripts in single cells. Nat Biotechnol. (2017) 35:936-9. doi: 10.1038/nbt.3973

86. Shahi P, Kim SC, Haliburton JR, Gartner ZJ, Abate AR. Abseq: ultrahighthroughput single cell protein profiling with droplet microfluidic barcoding. Sci Rep. (2017) 7:44447. doi: 10.1038/srep44447

87. Stoeckius M, Hafemeister C, Stephenson W, Houck-Loomis B, Chattopadhyay PK, Swerdlow $\mathrm{H}$, et al. Simultaneous epitope and transcriptome measurement in single cells. Nat Methods. (2017) 14:865-8. doi: $10.1038 /$ nmeth. 4380

88. Goswami S, Walle T, Cornish AE, Basu S, Anandhan S, Fernandez I, et al. Immune profiling of human tumors identifies CD73 as a combinatorial target in glioblastoma. Nat Med. (2020) 26:39-46. doi: 10.1038/s41591-019-0694-x

89. Gubin MM, Esaulova E, Ward JP, Malkova ON, Runci D, Wong P, et al. High-dimensional analysis delineates myeloid and lymphoid compartment remodeling during successful immune-checkpoint cancer therapy. Cell. (2018) 175:1443. doi: 10.1016/j.cell.2018.11.003

90. Buenrostro JD, Wu B, Chang HY, Greenleaf WJ. ATAC-seq: a method for assaying chromatin accessibility genome-wide. Curr Protoc Mol Biol. (2015) 109:21.29.1-21.29.9. doi: 10.1002/0471142727.mb2129s109

91. Mair F, Hartmann FJ, Mrdjen D, Tosevski V, Krieg C, Becher B. The end of gating? An introduction to automated analysis of high dimensional cytometry data. Eur J Immunol. (2016) 46:34-43. doi: 10.1002/eji.2015 45774

92. Saeys Y, Van Gassen S, Lambrecht BN. Computational flow cytometry: helping to make sense of high-dimensional immunology data. Nat Rev Immunol. (2016) 16:449-62. doi: 10.1038/nri.2016.56

93. Brummelman J, Haftmann C, Nunez NG, Alvisi G, Mazza EMC, Becher B, et al. Development, application and computational analysis of high-dimensional fluorescent antibody panels for single-cell flow cytometry. Nat Protoc. (2019) 14:1946-69. doi: 10.1038/s41596-0190166-2

94. Mazza EMC, Brummelman J, Alvisi G, Roberto A, De Paoli F, Zanon V, et al. Background fluorescence and spreading error are major contributors of variability in high-dimensional flow cytometry data visualization by tdistributed stochastic neighboring embedding. Cytometry A. (2018) 93:78592. doi: $10.1002 /$ cyto.a. 23566
95. Becht E, McInnes L, Healy J, Dutertre CA, Kwok IWH, Ng LG, et al. Dimensionality reduction for visualizing single-cell data using UMAP. Nat Biotechnol. (2018) 37:38-44. doi: 10.1038/nbt.4314

96. Cheng Y, Wong MT, van der Maaten L, Newell EW. Categorical analysis of human $\mathrm{T}$ cell heterogeneity with one-dimensional soli-expression by nonlinear stochastic embedding. J Immunol. (2016) 196:924-32. doi: 10.4049/jimmunol.1501928

97. Lugli E, Pinti M, Nasi M, Troiano L, Ferraresi R, Mussi C, et al. Subject classification obtained by cluster analysis and principal component analysis applied to flow cytometric data. Cytometry A. (2007) 71:334-44. doi: 10.1002/cyto.a.20387

98. Levine JH, Simonds EF, Bendall SC, Davis KL, Amir el AD, Tadmor MD, et al. Data-driven phenotypic dissection of AML reveals progenitorlike cells that correlate with prognosis. Cell. (2015) 162:184-97. doi: 10.1016/j.cell.2015.05.047

99. Van Gassen S, Callebaut B, Van Helden MJ, Lambrecht BN, Demeester P, Dhaene T, et al. FlowSOM: using self-organizing maps for visualization and interpretation of cytometry data. Cytometry A. (2015) 87:636-45. doi: 10.1002/cyto.a.22625

100. Wang T, Li B, Nelson CE, Nabavi S. Comparative analysis of differential gene expression analysis tools for single-cell RNA sequencing data. BMC Bioinformatics. (2019) 20:40. doi: 10.1186/s12859-019-2599-6

101. Bendall SC, Davis KL, Amir el AD, Tadmor MD, Simonds EF, Chen TJ, et al. Single-cell trajectory detection uncovers progression and regulatory coordination in human B cell development. Cell. (2014) 157:714-25. doi: 10.1016/j.cell.2014.04.005

102. Packer J, Trapnell C. Single-cell multi-omics: an engine for new quantitative models of gene regulation. Trends Genet. (2018) 34:653-65. doi: 10.1016/j.tig.2018.06.001

103. Trapnell C, Cacchiarelli D, Grimsby J, Pokharel P, Li S, Morse M, et al. The dynamics and regulators of cell fate decisions are revealed by pseudotemporal ordering of single cells. Nat Biotechnol. (2014) 32:381-6. doi: $10.1038 /$ nbt.2859

104. Saelens W, Cannoodt R, Todorov H, Saeys Y. A comparison of singlecell trajectory inference methods. Nat Biotechnol. (2019) 37:547-54. doi: 10.1038/s41587-019-0071-9

105. Todorov H, Saeys Y. Computational approaches for high-throughput singlecell data analysis. FEBS J. (2019) 286:1451-67. doi: 10.1111/febs.14613

106. Gonzalez-Silva L, Quevedo L, Varela I. Tumor functional heterogeneity unraveled by scRNA-seq technologies. Trends Cancer. (2020) 6:13-9. doi: 10.1016/j.trecan.2019.11.010

107. Navin N, Kendall J, Troge J, Andrews P, Rodgers L, McIndoo J, et al. Tumour evolution inferred by single-cell sequencing. Nature. (2011) 472:904. doi: 10.1038/nature09807

108. Chevrier S, Levine JH, Zanotelli VRT, Silina K, Schulz D, Bacac M, et al. An immune atlas of clear cell renal cell carcinoma. Cell. (2017) 169:736-49.e18. doi: 10.1016/j.cell.2017.04.016

109. Guo X, Zhang Y, Zheng L, Zheng C, Song J, Zhang Q, et al. Global characterization of $\mathrm{T}$ cells in non-small-cell lung cancer by single-cell sequencing. Nat Med. (2018) 24:978-85. doi: 10.1038/s41591-018-0045-3

110. Wagner J, Rapsomaniki MA, Chevrier S, Anzeneder T, Langwieder C, Dykgers A, et al. A single-cell atlas of the tumor and immune ecosystem of human breast cancer. Cell. (2019) 177:1330-45.e18. doi: 10.1016/j.cell.2019.03.005

111. Zheng C, Zheng L, Yoo JK, Guo H, Zhang Y, Guo X, et al. Landscape of infiltrating $\mathrm{T}$ cells in liver cancer revealed by single-cell sequencing. Cell. (2017) 169:1342-56.e16. doi: 10.1016/j.cell.2017.05.035

112. Alfei F, Kanev K, Hofmann M, Wu M, Ghoneim HE, Roelli P, et al. TOX reinforces the phenotype and longevity of exhausted $\mathrm{T}$ cells in chronic viral infection. Nature. (2019) 571:265-9. doi: 10.1038/s41586-019-1326-9

113. Khan O, Giles JR, McDonald S, Manne S, Ngiow SF, Patel KP, et al. TOX transcriptionally and epigenetically programs CD8+ T cell exhaustion. Nature. (2019) 571:211-8. doi: 10.1038/s41586-019-1325-x

114. Scott AC, Dundar F, Zumbo P, Chandran SS, Klebanoff CA, Shakiba M, et al. TOX is a critical regulator of tumour-specific T cell differentiation. Nature. (2019) 571:270-4. doi: 10.1038/s41586-019-1324-y

115. Seo H, Chen J, Gonzalez-Avalos E, Samaniego-Castruita D, Das A, Wang $\mathrm{YH}$, et al. TOX and TOX2 transcription factors cooperate with NR4A 
transcription factors to impose CD8+ T cell exhaustion. Proc Natl Acad Sci USA. (2019) 116:12410-5. doi: 10.1073/pnas.1905675116

116. Clarke J, Panwar B, Madrigal A, Singh D, Gujar R, Wood O, et al. Singlecell transcriptomic analysis of tissue-resident memory T cells in human lung cancer. J Exp Med. (2019) 216:2128-49. doi: 10.1084/jem.20190249

117. Savas P, Virassamy B, Ye C, Salim A, Mintoff CP, Caramia F, et al. Singlecell profiling of breast cancer $\mathrm{T}$ cells reveals a tissue-resident memory subset associated with improved prognosis. Nat Med. (2018) 24:986-93. doi: 10.1038/s41591-018-0078-7

118. Blank CU, Haining WN, Held W, Hogan PG, Kallies A, Lugli E, et al. Defining 'T cell exhaustion'. Nat Rev Immunol. (2019) 19:665-74. doi: 10.1038/s41577-019-0221-9

119. Provine NM, Klenerman P. MAIT cells in health and disease. Annu Rev Immunol. (2020) 38:203-28. doi: 10.1146/annurev-immunol-080719-015428

120. Yan J, Allen S, McDonald E, Das I, Mak JYW, Liu L, et al. MAIT cells promote tumor initiation, growth, and metastases via tumor MR1. Cancer Discov. (2020) 10:124-41. doi: 10.1158/2159-8290.CD-19-0569

121. Zhang L, Yu X, Zheng L, Zhang Y, Li Y, Fang Q, et al. Lineage tracking reveals dynamic relationships of T cells in colorectal cancer. Nature. (2018) 564:268-72. doi: 10.1038/s41586-018-0694-x

122. Yong YK, Saeidi A, Tan HY, Rosmawati M, Enstrom PF, Batran RA, et al. Hyper-expression of PD-1 is associated with the levels of exhausted and dysfunctional phenotypes of circulating $\mathrm{CD} 161^{++}$TCR iValpha7.2+ mucosal-associated invariant $\mathrm{T}$ cells in chronic hepatitis $\mathrm{B}$ virus infection. Front Immunol. (2018) 9:472. doi: 10.3389/fimmu.2018.00472

123. Durante MA, Rodriguez DA, Kurtenbach S, Kuznetsov JN, Sanchez MI, Decatur CL, et al. Single-cell analysis reveals new evolutionary complexity in uveal melanoma. Nat Commun. (2020) 11:496. doi: 10.1038/s41467-019-14256-1

124. Heppt MV, Steeb T, Schlager JG, Rosumeck S, Dressler C, Ruzicka $\mathrm{T}$, et al. Immune checkpoint blockade for unresectable or metastatic uveal melanoma: a systematic review. Cancer Treat Rev. (2017) 60:44-52. doi: 10.1016/j.ctrv.2017.08.009

125. Sen DR, Kaminski J, Barnitz RA, Kurachi M, Gerdemann U, Yates KB, et al. The epigenetic landscape of T cell exhaustion. Science. (2016) 354:1165-69. doi: 10.1126/science.aae 0491

126. de Andrade LF, Lu Y, Luoma A, Ito Y, Pan D, Pyrdol JW, et al. Discovery of specialized NK cell populations infiltrating human melanoma metastases. JCI Insight. (2019) 4:e133103. doi: 10.1172/jci.insight.133103

127. Engblom C, Pfirschke C, Pittet MJ. The role of myeloid cells in cancer therapies. Nat Rev Cancer. (2016) 16:447-62. doi: 10.1038/nrc.2016.54

128. Gabrilovich DI, Ostrand-Rosenberg S, Bronte V. Coordinated regulation of myeloid cells by tumours. Nat Rev Immunol. (2012) 12:253-68. doi: $10.1038 /$ nri3175

129. Krieg C, Nowicka M, Guglietta S, Schindler S, Hartmann FJ, Weber LM, et al. High-dimensional single-cell analysis predicts response to anti-PD-1 immunotherapy. Nat Med. (2018) 24:144-53. doi: 10.1038/nm.4466

130. Lavin Y, Kobayashi S, Leader A, Amir ED, Elefant N, Bigenwald C, et al. Innate immune landscape in early lung adenocarcinoma by paired single-cell analyses. Cell. (2017) 169:750-65.e17. doi: 10.1016/j.cell.2017.04.014

131. Zhang Q, He Y, Luo N, Patel SJ, Han Y, Gao R, et al. Landscape and dynamics of single immune cells in hepatocellular carcinoma. Cell. (2019) 179:829-45.e20. doi: 10.1016/j.cell.2019.10.003

132. Merad M, Sathe P, Helft J, Miller J, Mortha A. The dendritic cell lineage: ontogeny and function of dendritic cells and their subsets in the steady state and the inflamed setting. Annu Rev Immunol. (2013) 31:563-604. doi: 10.1146/annurev-immunol-020711-074950

133. Daud AI, Loo K, Pauli ML, Sanchez-Rodriguez R, Sandoval PM, Taravati K, et al. Tumor immune profiling predicts response to anti-PD-1 therapy in human melanoma. J Clin Invest. (2016) 126:3447-52. doi: 10.1172/JCI87324

134. Huang AC, Postow MA, Orlowski RJ, Mick R, Bengsch B, Manne S, et al. Tcell invigoration to tumour burden ratio associated with anti-PD-1 response. Nature. (2017) 545:60-5. doi: 10.1038/nature22079

135. Kamphorst AO, Pillai RN, Yang S, Nasti TH, Akondy RS, Wieland A, et al. Proliferation of PD-1+ CD8 T cells in peripheral blood after PD-1-targeted therapy in lung cancer patients. Proc Natl Acad Sci USA. (2017) 114:4993-8. doi: $10.1073 /$ pnas. 1705327114
136. Wei SC, Levine JH, Cogdill AP, Zhao Y, Anang NAS, Andrews $\mathrm{MC}$, et al. Distinct cellular mechanisms underlie anti-CTLA-4 and anti-PD-1 checkpoint blockade. Cell. (2017) 170:1120-33.e17. doi: 10.1016/j.cell.2017.07.024

137. Jerby-Arnon L, Shah P, Cuoco MS, Rodman C, Su MJ, Melms JC, et al. A cancer cell program promotes $\mathrm{T}$ cell exclusion and resistance to checkpoint blockade. Cell. (2018) 175:984-97.e24. doi: 10.1016/j.cell.2018.09.006

138. Thommen DS, Koelzer VH, Herzig P, Roller A, Trefny M, Dimeloe S, et al. A transcriptionally and functionally distinct PD-1+CD8+ T cell pool with predictive potential in non-small-cell lung cancer treated with PD-1 blockade. Nat Med. (2018) 24:994-1004. doi: 10.1038/s41591-018-0057-z

139. Sade-Feldman M, Yizhak K, Bjorgaard SL, Ray JP, de Boer CG, Jenkins RW, et al. Defining $\mathrm{T}$ cell states associated with response to checkpoint immunotherapy in melanoma. Cell. (2018) 175:998-1013.e20. doi: 10.1016/j.cell.2018.10.038

140. Wieland A, Kamphorst AO, Adsay NV, Masor JJ, Sarmiento J, Nasti TH, et al. $\mathrm{T}$ cell receptor sequencing of activated CD8 $\mathrm{T}$ cells in the blood identifies tumor-infiltrating clones that expand after PD-1 therapy and radiation in a melanoma patient. Cancer Immunol Immunother. (2018) 67:1767-76. doi: 10.1007/s00262-018-2228-7

141. Zappasodi R, Budhu S, Hellmann MD, Postow MA, Senbabaoglu Y, Manne $\mathrm{S}$, et al. Non-conventional inhibitory CD4+Foxp3(-)PD-1(hi) T cells as a biomarker of immune checkpoint blockade activity. Cancer Cell. (2018) 33:1017-32.e7. doi: 10.1016/j.ccell.2018.05.009

142. Gide TN, Quek C, Menzies AM, Tasker AT, Shang P, Holst J, et al. Distinct immune cell populations define response to anti-PD-1 monotherapy and anti-PD-1/anti-CTLA-4 combined therapy. Cancer Cell. (2019) 35:23855.e6. doi: 10.1016/j.ccell.2019.01.003

143. Schalper KA, Rodriguez-Ruiz ME, Diez-Valle R, Lopez-Janeiro A, Porciuncula A, Idoate MA, et al. Neoadjuvant nivolumab modifies the tumor immune microenvironment in resectable glioblastoma. Nat Med. (2019) 25:470-6. doi: 10.1038/s41591-018-0339-5

144. Li H, van der Leun AM, Yofe I, Lubling Y, Gelbard-Solodkin D, van Akkooi ACJ, et al. Dysfunctional CD8 T cells form a proliferative, dynamically regulated compartment within human melanoma. Cell. (2019) 176:77589.e18. doi: 10.1016/j.cell.2018.11.043

145. Huang AC, Orlowski RJ, Xu X, Mick R, George SM, Yan PK, et al. A single dose of neoadjuvant PD-1 blockade predicts clinical outcomes in resectable melanoma. Nat Med. (2019) 25:454-61. doi: 10.1038/s41591-019-0357-y

146. Yost KE, Satpathy AT, Wells DK, Qi Y, Wang C, Kageyama R, et al. Clonal replacement of tumor-specific T cells following PD-1 blockade. Nat Med. (2019) 25:1251-9. doi: 10.1038/s41591-019-0522-3

147. Helmink BA, Reddy SM, Gao J, Zhang S, Basar R, Thakur R, et al. B cells and tertiary lymphoid structures promote immunotherapy response. Nature. (2020) 577:549-55. doi: 10.1038/s41586-019-1922-8

148. Taniuchi I. CD4 helper and CD8 cytotoxic $\mathrm{T}$ cell differentiation. Annu Rev Immunol. (2018) 36:579-601. doi: 10.1146/annurev-immunol-042617-053411

149. van der Leun AM, Thommen DS, Schumacher TN. CD8+ T cell states in human cancer: insights from single-cell analysis. Nat Rev Cancer. (2020). doi: 10.1038/s41568-019-0235-4

150. Simoni Y, Becht E, Fehlings M, Loh CY, Koo SL, Teng KWW, et al. Bystander CD8 + T cells are abundant and phenotypically distinct in human tumour infiltrates. Nature. (2018) 557:575-9. doi: 10.1038/s41586-018-0130-2

151. Harjes U. T cells pass on the baton during checkpoint inhibition. Nat Rev Cancer. (2019) 19:546. doi: 10.1038/s41568-019-0194-9

152. Fridman WH, Zitvogel L, Sautes-Fridman C, Kroemer G. The immune contexture in cancer prognosis and treatment. Nat Rev Clin Oncol. (2017) 14:717-34. doi: 10.1038/nrclinonc.2017.101

153. Friedman KM, Prieto PA, Devillier LE, Gross CA, Yang JC, Wunderlich JR, et al. Tumor-specific CD4+ melanoma tumor-infiltrating lymphocytes. J Immunother. (2012) 35:400-8. doi: 10.1097/CJI.0b013e31825 $898 \mathrm{c} 5$

154. Wang K, Shen T, Siegal GP, Wei S. The CD4/CD8 ratio of tumorinfiltrating lymphocytes at the tumor-host interface has prognostic value in triple-negative breast cancer. Hum Pathol. (2017) 69:110-17. doi: 10.1016/j.humpath.2017.09.012 
155. Magen A, Nie J, Ciucci T, Tamoutounour S, Zhao Y, Mehta M, et al. Singlecell profiling defines transcriptomic signatures specific to tumor-reactive versus virus-responsive CD4+ T cells. Cell Rep. (2019) 29:3019-32.e6. doi: 10.1016/j.celrep.2019.10.131

156. Tirosh I, Izar B, Prakadan SM, Wadsworth MH, 2nd, Treacy D, Trombetta JJ, et al. Dissecting the multicellular ecosystem of metastatic melanoma by single-cell RNA-seq. Science. (2016) 352:189-96. doi: 10.1126/science.aad0501

157. Antonioli L, Pacher P, Vizi ES, Hasko G. CD39 and CD73 in immunity and inflammation. Trends Mol Med. (2013) 19:355-67. doi: 10.1016/j.molmed.2013.03.005

158. Azambuja JH, Gelsleichter NE, Beckenkamp LR, Iser IC, Fernandes MC, Figueiro F, et al. CD73 downregulation decreases in vitro and in vivo glioblastoma growth. Mol Neurobiol. (2019) 56:3260-79. doi: $10.1007 / \mathrm{s} 12035-018-1240-4$
159. Cabrita R, Lauss M, Sanna A, Donia M, Skaarup Larsen M, Mitra S, et al. Tertiary lymphoid structures improve immunotherapy and survival in melanoma. Nature. (2020) 577:561-5. doi: 10.1038/s41586-019-1914-8

Conflict of Interest: The authors declare that the research was conducted in the absence of any commercial or financial relationships that could be construed as a potential conflict of interest.

Copyright (C) 2020 Gibellini, De Biasi, Porta, Lo Tartaro, Depenni, Pellacani, Sabbatini and Cossarizza. This is an open-access article distributed under the terms of the Creative Commons Attribution License (CC BY). The use, distribution or reproduction in other forums is permitted, provided the original author(s) and the copyright owner(s) are credited and that the original publication in this journal is cited, in accordance with accepted academic practice. No use, distribution or reproduction is permitted which does not comply with these terms. 